This document is the accepted manuscript version of the following article:

Verboekend, D., Keller, T. C., Milina, M., Hauert, R., \& Pérez-Ramírez, J. (2013). Hierarchy brings function: mesoporous clinoptilolite and L zeolite catalysts synthesized by tandem

acid-base treatments. Chemistry of Materials, 25(9), 1947-1959.

https://doi .org/10.1021/cm4006103

\title{
Hierarchy Brings Function: Mesoporous Clinoptilolite and L Zeolite Catalysts Synthesized by Tandem Acid-Base Treatments
}

\author{
Danny Verboekend,${ }^{\dagger}$ Tobias C. Keller, ${ }^{\dagger}$ Maria Milina, ${ }^{\dagger}$ Roland Hauert,${ }^{\ddagger}$ and Javier Pérez-Ramírez ${ }^{*} \dagger$ \\ IInstitute for Chemical and Bioengineering, Department of Chemistry and Applied Biosciences, ETH Zurich, Wolf- \\ gang-Pauli-Strasse 10, CH-8093, Zurich, Switzerland. ‡Empa, Swiss Federal Laboratories for Materials Science and \\ Technology, Überlandstrasse 129, CH-86oo Dübendorf, Switzerland.
}

KEYWORDS: Hierarchical zeolites, Clinoptilolite, HEU, LTL, Dealumination, Desilication, Catalysis

\begin{abstract}
Hierarchical clinoptilolite and L zeolites are prepared using optimized tandem dealumination-desilication treatments. The main challenge in the post-synthetic modification of these zeolites is the high $\mathrm{Al}$ content, requiring a tailored dealumination prior to the desilication step. For natural clinoptilolite sequential acid treatments using aqueous $\mathrm{HCl}$ solutions were applied, while for $\mathrm{L}$ a controlled dealumination using ammonium hexafluorosilicate is required. Subsequent desilication by $\mathrm{NaOH}$ treatment yields mesopore surfaces of up to 4-fold (clinoptilolite: $64 \mathrm{~m}^{2} \mathrm{~g}^{-1}$, $\mathrm{L}: 135 \mathrm{~m}^{2} \mathrm{~g}^{-1}$ ) relative to the parent zeolite (clinoptilolite: $15 \mathrm{~m}^{2} \mathrm{~g}^{-1}, \mathrm{~L}: 45 \mathrm{~m}^{2} \mathrm{~g}^{-1}$ ). A thorough characterization sheds light on the composition, crystallinity, porosity, morphology, coordination, and acidity of the modified clinoptilolite and L zeolites. It is elaborated that, besides the degree of dealumination, the resulting $\mathrm{Al}$ distribution is a critical precondition for the following mesopore formation by desilication. Adsorption experiments of $\mathrm{Cu}^{2+}$ and methylene blue from aqueous solutions and the catalytic evaluation in alkylations and Knoevenagel condensation evidence the superiority of the hierarchical zeolites, compared to their purely microporous counterparts. Finally, the post-synthetic routes for clinoptilolite and L are generalized with other recently reported modification strategies, and presented in a comprehensive overview.
\end{abstract}

\section{Introduction}

Since the discovery of large monoclinic deposits half a century ago, natural zeolites have found large-scale applications in construction, waste water treatment, and agriculture. Of the roughly 20 different types of natural zeolites, clinoptilolite is by far the most abundant, and accordingly stands as the most consumed zeolite today by volume. ${ }^{1,2}$ Clinoptilolite (HEU topology) is iso-structural with the more Al-rich, but less stable, heulandite and typically comprises a framework $\mathrm{Si} / \mathrm{Al}$ ratio of 5 . The HEU framework features 2-dimensional elliptical 10 and 8-ring micropores of sizes $3.1 \times 7.5$ (10-ring), 3.6×4.6 (8-ring), and 2.8×4.7 $\AA$ (8-ring). ${ }^{1-4}$

Several zeolites with 10-ring micropores, e.g. ZSM-5, ZSM-22, ferrierite, excel based on their superior shapeselectivities in numerous catalyzed reactions as isomerizations, alkylations, and methanol to olefins.5-7 Nevertheless, the role of clinoptilolite as catalysts is to date hardly existent. ${ }^{4}$ Several studies ${ }^{8,9}$ focused on using clinoptilolite in the isomerization of $n$-butene to isobutene, since ferrierite, having a similar micropore structure, displays an exceptional selectivity at reasonable activity in this reaction. ${ }^{10}$ However, although even higher selectivities were attained, clinoptilolite proved an overall inefficient catalyst based on a much lower activity. ${ }^{8,9}$

Shortly after synthetic zeolites were recognized in the 1950 ond 1960 s as a superior class of catalysts, various chemical treatments to modify previously-grown zeolites were reported. Initially, these were aimed principally at enhancing catalytic performance by changing the stability and/or the amount (and strength) of acid sites. The latter was achieved predominately using steaming or acid treatment, most notoriously on Y zeolite. ${ }^{11}$ Nevertheless, during the last decade, post-synthetic modifications proved not only able to enhance stability and acidity, they also form a powerful tool to introduce secondary porosity in zeolite crystals. ${ }^{12,13}$ The latter is of critical relevance since in most catalyzed reactions the zeolite acid sites are poorly utilized due to access and diffusion limitations, ${ }^{14-16}$ as was demonstrated in, for example, catalytic cracking of vacuum gas oil ${ }^{17}$ and alkane hydro-isomerization. ${ }^{18}$

With the exception of the high-alumina zeolites, e.g. $\mathrm{X}$ and $A,{ }^{19}$ the mesopore formation in zeolites by postsynthetic modification is centered primarily around a base leaching, or desilication, step. In addition, a subsequent mild acid wash can be used to remove any residual debris that may have formed during the base leaching. ${ }^{12}$ However, for a number of key zeolites, e.g. mordenite ${ }^{20}$ and $\mathrm{Y}^{21}$ an antecedent framework dealumination is required to increase the bulk $\mathrm{Si} / \mathrm{Al}$ ratio to facilitate the dissolution in alkaline media. Still, the influence of the efficiency of this dealumination step on the following steps in the post-synthetic modifications sequence has not been addressed. The latter is striking since both the amount $^{22,23}$ and the location of aluminum ${ }^{24,25}$ have a pronounced influence on the dissolution behavior of zeolite crystals upon base treatment. 
Table 1. Sample notation and treatment conditions

\begin{tabular}{|c|c|c|c|c|c|c|}
\hline Treatment & Reagent & $C(\mathrm{M})$ & $C_{\text {zeolite }}\left(\mathrm{g} \mathrm{L}^{-1}\right)$ & $T\left({ }^{\circ} \mathrm{C}\right)$ & $t(\mathrm{~h})$ & Repetitions (\#) \\
\hline $\mathrm{A}_{1}$ & $\mathrm{HCl}$ & 1 & 67 & 100 & 4 & 4 \\
\hline $\mathrm{A} 2$ & $\mathrm{HCl}$ & 1 & 67 & 100 & 4 & 1 \\
\hline $\mathrm{A} 3^{\mathrm{a}}$ & $\left(\mathrm{NH}_{4}\right)_{2} \mathrm{SiF}_{6}$ & n. a. & n. a. & 75 and 95 & 4.2 and 16 & 1 \\
\hline $\mathrm{A}_{4}$ & $\mathrm{Na}_{2} \mathrm{H}_{2}$ EDTA & 0.11 & 67 & 100 & 6 & 1 \\
\hline $\mathrm{B} 1$ & $\mathrm{NaOH}$ & 0.2 & 33 & 65 & 0.5 & 1 \\
\hline $\mathrm{Na}$ & $\mathrm{NaCl}$ & 2 & 10 & 25 & 24 & 1 \\
\hline $\mathrm{NH}_{4}$ & $\mathrm{NH}_{4} \mathrm{Cl}$ & 1 & 10 & 25 & 16 & 3 \\
\hline Cs & $\mathrm{CsCl}$ & 0.1 & 10 & 25 & 24 & 1 \\
\hline $\mathrm{Cu}$ & $\mathrm{Cu}\left(\mathrm{NO}_{3}\right)_{2}$ & 0.005 & 10 & 25 & 3 & 1 \\
\hline MB & $\mathrm{C}_{16} \mathrm{H}_{18} \mathrm{ClN}_{3} \mathrm{~S}$ & $10^{-5}$ & 0.125 & 25 & 24 & 1 \\
\hline
\end{tabular}

${ }^{\mathrm{a}}$ Further details of $\mathrm{A}_{3}$ are described in Section 2.

Clinoptilolite zeolites have been previously exposed to modifications by acid or base treatments. For example, acid treatments, aimed at framework dealumination, led to enhanced sorption and mesopore formation. ${ }^{26-28} \mathrm{How}^{-}$ ever, in catalyzed reactions, the dealuminated clinoptilolite displayed even lower activities than the parent zeolite. ${ }^{8,29}$ Also direct base treatment originated some mesopore formation, ${ }^{30}$ that is, the treated zeolite displayed merely 50\% additional external surface, while no catalytic evaluation was reported. Still, the possibility to strategically combine base and acid treatments to yield superior hierarchical zeolite catalysts (or adsorbents) was never attempted.

In this contribution we prepare hierarchical clinoptilolite by a tailored tandem dealumination-desilication treatment (Scheme 1). The latter strategy is concomitantly verified for the $\mathrm{L}$ zeolite, displaying also a high $\mathrm{Al}$ content and requiring a controlled dealumination. This is valuable as $\mathrm{Pt} / \mathrm{K}-\mathrm{L}$ is a relevant catalyst for hexane aromatization, ${ }^{6,31}$ and was thus far never prepared in a crystalline hierarchical form. A thorough characterization assesses a wide variety of physico-chemical properties, highlighting the crucial role of both the $\mathrm{Al}$ content and distribution in the sequence of post-synthetic modifications. The superiority of the hierarchical clinoptilolite and $\mathrm{L}$ zeolites is demonstrated in the adsorption of $\mathrm{Cu}^{2+}$ and

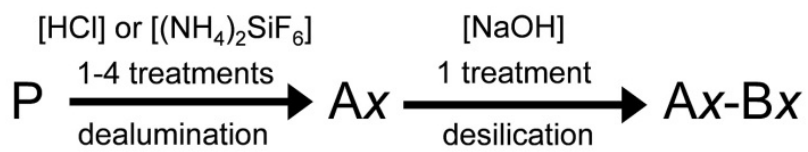

Scheme 1. Sequence of post-synthetic treatments over parent clinoptilolite and $\mathrm{L}$ to prepare hierarchical zeolites. The codes 'A' and 'B' stand for acid and base treatment respectively. The suffix ' $x$ ' represents integers for further specification. methylene blue from aqueous solutions, and in different acid and base-catalyzed reactions. The latter experiments unambiguously establish that the external surface area obtained by dealumination-desilication, is superior to that obtained by dealumination alone. Moreover, the boosted activity sheds new light on the wider use of clinoptilolite in catalytic applications. Finally, we generalize recent post-synthetic modifications strategies to prepare hierarchical zeolites based on a number of key criteria, e.g. $\mathrm{Si} / \mathrm{Al}$ ratio and micropore size.

\section{Experimental}

Materials and treatments: The parent clinoptilolite (code 'C-P', sodium form, >97\% purity, U.S. standard sieve mesh No. 100) was kindly provided by KMI Zeolite, ${ }^{32}$ located in Sandy Valley, Nevada, United States. The parent $\mathrm{L}$ (code 'L-P') was supplied by TOSOH (5ooKOA, potassium form, $\mathrm{Si} / \mathrm{Al}=\mathbf{2 . 9}$ ). The prefixes ' $\mathrm{C}$ ' and ' $\mathrm{L}$ ' were used to refer to clinoptilolite and L-type zeolites, respectively. A commercial ZSM-5 (code 'ZSM-5', CBV 3024E, Zeolyst International, nominal $\mathrm{Si} / \mathrm{Al}=15)$, calcined at $550^{\circ} \mathrm{C}$ for $5 \mathrm{~h}$ (ramp rate: $5^{\circ} \mathrm{C} \mathrm{min}^{-1}$ ), was used as a reference material in alkylation experiments.

Post-synthetic modifications were performed by contacting batches of zeolite with the aqueous solutions and conditions reported in Tables 1 and S1. Treatments involving volumes of up to $100 \mathrm{~cm}^{3}$ were performed under magnetic stirring using an Easymax ${ }^{\mathrm{TM}} 102$ instrument from Mettler Toledo. Treatments involving solutions of $100-500 \mathrm{~cm}^{3}$ were executed under magnetic stirring in a round-bottomed flask equipped with a reflux condenser. In a typical experiment, the zeolite sample (0.3-20 g) was added to a vigorously stirred solution of the desired solute, molarity $(0.1-2 \mathrm{M})$, and temperature $\left(25-100^{\circ} \mathrm{C}\right)$, and was left to react for the required time (0.5-24 h). After- 
wards, the reaction was quenched and the resulting solid was filtered, washed using distilled water, and dried overnight at $65^{\circ} \mathrm{C}$. The dealumination treatment on zeolite $\mathrm{L}$ (treatment ' $\mathrm{A} 3^{\prime}$ ') was performed in a different manner, that is, according to the method of Breck and Skeels. ${ }^{33}$ Thus, the parent L zeolite (10 g, brought to the ammonium form using ion exchange: treatment ' $\mathrm{NH}_{4}$ ') was suspended under vigorous stirring in $100 \mathrm{~cm}^{3}$ of distilled water at $75^{\circ} \mathrm{C}$. Next, a solution of $50 \mathrm{~cm}^{3}$ distilled water containing $3.36 \mathrm{~g}\left(\mathrm{NH}_{4}\right)_{2} \mathrm{SiF}_{6}$ was added to the suspension dropwise at a rate of $12 \mathrm{~cm}^{3} \mathrm{~h}^{-1}$. After addition of the fluorosilicate, the slurry was heated to $95^{\circ} \mathrm{C}$ and maintained at this temperature for $16 \mathrm{~h}$. Finally, the obtained product was filtered, thoroughly washed, and dried overnight at $65^{\circ} \mathrm{C}$. All solids (except samples 'C-A1' and 'C-A1$\mathrm{B} 1-\mathrm{A}_{2}$ ') were brought to the protonic form (labeled ' $\mathrm{H}$ ') prior to acidity characterization or catalytic evaluation. The latter was achieved by ion exchange to the ammonium form (treatment ' $\mathrm{NH}_{4}$ '), followed by a calcination in air $\left(16 \mathrm{~h}\right.$ at $400^{\circ} \mathrm{C}$ for clinoptilolite and $4 \mathrm{~h}$ at $500^{\circ} \mathrm{C}$ for $\mathrm{L}$, ramp rate $5^{\circ} \mathrm{C} \mathrm{min}^{-1}$ in both cases). Conversely, before $\mathrm{Cu}^{2+}$ and methylene blue adsorption tests, the samples were brought to the sodium form (treatment ' $\mathrm{Na}$ '). Prior to Knoevenagel condensations, the zeolites were brought to the cesium form (treatment ' $\mathrm{Cs}$ ').

Characterization: Powder X-ray diffraction (XRD) patterns were acquired in a PANalytical X'Pert PRO-MPD diffractometer equipped with Bragg-Brentano geometry and $\mathrm{Ni}$-filtered $\mathrm{Cu} \mathrm{K} \alpha$ radiation $(\lambda=0.1541 \mathrm{~nm})$. Data were recorded in the $2 \theta$ range of $3-60^{\circ}$ with an angular step size of $0.05^{\circ}$ and a counting time of $8 \mathrm{~s}$ per step. $\mathrm{Si}$ and $\mathrm{Al}$ concentrations in the bulk of the solids were determined by inductively coupled plasma optical emission spectroscopy (ICP-OES) on a Horiba Ultima 2 instrument equipped with photomultiplier tube detection. The relative abundance of $\mathrm{Si}$ and $\mathrm{Al}$ on the surface of the solids was ascertained using X-ray photoelectron spectroscopy (XPS) performed on a Physical Electronics Quantum 2000 photoelectron spectrometer using monochromatic $\mathrm{Al} \mathrm{K \alpha}$ radiation $(\lambda=0.834 \mathrm{~nm})$. The analyzer pass energy used was $46.95 \mathrm{eV}$ to yield a total analyzer energy resolution of $0.95 \mathrm{eV}$ for $\mathrm{Ag}$ 3d electrons. Atomic concentrations were obtained from the different peak areas using the built in PHI sensitivity factors. Transmission electron microscopy (TEM) were performed using FEI Tecnai F3o and Phillips CM12 microscopes. Scanning electron microscopy (SEM) was carried out on a Zeiss Gemini 1530 FEG microscope. Nitrogen sorption at $-196^{\circ} \mathrm{C}$ was carried out in a Micromeritics TriStar II instrument. Prior to the measurement, the samples were degassed in vacuum at $300^{\circ} \mathrm{C}$ for $3 \mathrm{~h}$. The $t$-plot method was used to discriminate between micro- and mesoporosity. The mesopore size distribution was obtained by the Barrett-Joyner-Halenda (BJH) model applied to the adsorption branch of the isotherm. Highresolution low-pressure $\mathrm{Ar}$ adsorption isotherms were recorded at $-196^{\circ} \mathrm{C}$ on a Micromeritics ASAP 2020 analyzer after evacuation at $300^{\circ} \mathrm{C}$ for $8 \mathrm{~h}$. The hybrid nonlinear density functional theory (NLDFT) model describing argon adsorption in cylindrical micro- and mesopores was used to calculate the pore size distribution. Mercury porosimetry was performed in the pressure range from vacuum to 4000 bar on a Micromeritics Autopore IV 9510. Degassing was undertaken in situ. A contact angle of $140^{\circ}$ for mercury and the Washburn equation were used to derive the corresponding pore size distribution. Temperature-programmed desorption of ammonia $\left(\mathrm{NH}_{3}-\mathrm{TPD}\right)$ was carried out in a Thermo TPDRO 1100 unit equipped with a thermal conductivity detector. The zeolite $(100 \mathrm{mg}$ ) was pretreated at $400^{\circ} \mathrm{C}$ in He flow $\left(20 \mathrm{~cm}^{3} \mathrm{~min}^{-1}\right)$ for $2 \mathrm{~h}$. Afterwards, 10 vol. $\% \mathrm{NH}_{3}$ in $\mathrm{He}\left(20 \mathrm{~cm}^{3} \mathrm{~min}^{-1}\right)$ was adsorbed at $200^{\circ} \mathrm{C}$ for $30 \mathrm{~min}$ followed by He purging at the same temperature for $1 \mathrm{~h}$. This procedure was repeated three times. Desorption of $\mathrm{NH}_{3}$ was monitored in the range $200-700^{\circ} \mathrm{C}$ using a ramp rate of $10{ }^{\circ} \mathrm{C} \mathrm{min}$. . Fourier transform infrared (FTIR) spectroscopy was carried out in a Bruker VERTEX 70 spectrometer equipped with a SpectraTech Collector II diffuse reflectance (DRIFTS) accessory. Prior to the measurement, the samples were dried at $400^{\circ} \mathrm{C}$ in flowing $\mathrm{N}_{2}\left(100 \mathrm{~cm}^{3} \mathrm{~min}^{-1}\right)$ for $4 \mathrm{~h}$. Spectra were recorded under a $\mathrm{N}_{2}$ atmosphere at $200^{\circ} \mathrm{C}$, in the range of $650-4000 \mathrm{~cm}^{-1}$, by co-addition of 200 scans and with a nominal resolution of $4 \mathrm{~cm}^{-1} .{ }^{27} \mathrm{Al}$ magic angle spinning nuclear magnetic resonance (MAS NMR) spectroscopy was performed at a spinning speed of $10 \mathrm{kHz}$ on a Bruker Avance 400 spectrometer equipped with a $4 \mathrm{~mm}$ probe head and $4 \mathrm{~mm} \mathrm{ZrO}_{2}$ rotors at $182.4 \mathrm{MHz}$. Spectra were obtained using 4096 accumulations, $90^{\circ}$ pulses with a pulse length of $2.4 \mu \mathrm{s}$, a recycle delay of $0.25 \mathrm{~s}$, and with $\left(\mathrm{NH}_{4}\right) \mathrm{Al}\left(\mathrm{SO}_{4}\right)_{2} \cdot 12 \mathrm{H}_{2} \mathrm{O}$ as reference. ${ }^{29} \mathrm{Si}$ MAS-NMR spectra were recorded at a spinning speed of $10 \mathrm{kHz}$ on a Bruker Avance 700 NMR spectrometer equipped with a $4 \mathrm{~mm}$ probe head and $4 \mathrm{~mm} \mathrm{ZrO}_{2}$ rotors at $139.1 \mathrm{MHz}$. The spectra were acquired using 1024 accumulations, $90^{\circ}$ pulses with a pulse length of $12.5 \mu \mathrm{s}$, a recycle delay of $10 \mathrm{~s}$ and octakis(trimethylsiloxy)-silsesquioxane as reference. MAS NMR spectra were normalized to the sample weight in the rotors.

Adsorption experiments: Sorption tests of $\mathrm{Cu}^{2+}$ and methylene blue were performed using the conditions mentioned in Table 1 (treatment codes ' $\mathrm{Cu}$ ' and 'MB', respectively). The $\mathrm{Cu}^{2+}$ or methylene blue concentration of the solutions was measured after filtration by UV/Vis spectroscopy.

Catalytic testing: Toluene alkylation with benzyl alcohol was conducted in an Endeavor Catalyst Screening System $\left(5 \mathrm{~cm}^{3}\right.$ working reaction volume, Argonaut Technologies) at 5 bar. The pre-dried catalyst $(25 \mathrm{mg})$ was added to a mixture of toluene $(47 \mathrm{mmol}$ ) and benzyl alcohol (o.6 mmol). The alkylation of toluene with isopropanol was undertaken in glass pressure tubes $\left(10 \mathrm{~cm}^{3}\right.$ working reaction volume, Aldrich) under autogenous pressure. In this case, the pre-dried catalyst (50 $\mathrm{mg}$ ) was added to a mixture of toluene $(47 \mathrm{mmol})$ and isopropanol $(1.2 \mathrm{mmol})$. Ethylcyclohexane $(0.25 \mathrm{mmol})$ was used as the 
internal standard for both alkylations. Knoevenagel condensations were carried out in a Radleys Carousel 6 Plus equipped with $50 \mathrm{~cm}^{3}$ two-neck round bottom flasks. Experiments were performed under $\mathrm{N}_{2}$ atmosphere to prevent oxidation of benzaldehyde. In a typical experiment, malononitrile (4 mmol), benzaldehyde $(4 \mathrm{mmol})$, and $n$-decane $(5 \mathrm{mmol}$, used as internal standard), were added to $30 \mathrm{~cm}^{3}$ of toluene, and heated to $80^{\circ} \mathrm{C}$, after which the catalyst $(50 \mathrm{mg}$ ) was added. Liquid samples collected after alkylation or Knoevenagel reactions were analyzed using an HP 6890 gas chromatograph equipped with a $\mathrm{HP}_{5}$ capillary column and a flame ionization detector.

\section{Results and discussion}

The preparation of hierarchical clinoptilolite is described in Section 3.1, followed by an extended characterization in Section 3.2. The synthesis of hierarchical L zeolites is disclosed in Section 3.3, while the role of the framework dealumination as part of the post-synthetic sequence is discussed in greater detail in Section 3.4. In Section 3.5, the performance of hierarchical clinoptilolite and $L$ zeolites is evaluated in the adsorption of metal or dye from aqueous solutions and catalytically in different acid or base-catalyzed reactions. Finally, in Section 3.6, several recent post-synthetic strategies to prepare hierarchical zeolites are generalized forming a comprehensive overview.

\subsection{Synthesis of hierarchical clinoptilolite}

The starting clinoptilolite sample (C-P) used in this study displayed the typical XRD pattern of the HEU framework (Fig. 1a) and agglomerated sheet-like crystals (Figs. 2 and 3). In addition, a minor peak at $9^{\circ} 2 \theta$ can be discerned which relates to a minor $(<3 \%)$ phlogopite impurity. ${ }^{32}$ The latter did not affect the post-synthetic modifications in any way. Due to the narrow micropore channels, the as-received zeolite (sodium form) did not display any nitrogen uptake at low relative pressures, which was combined with minor uptake at $p / p_{0}>0.1$ (Fig. S1). Accordingly, neither any detectable micropore volume, nor any significant contribution in the $\mathrm{BJH}$ mesopore size distribution (Fig. 4b) were evidenced, and the mesopore surface area was only $15 \mathrm{~m}^{2} \mathrm{~g}^{-1}$ (Table 2 ). The protonic form (sample C-P-H) featured an accessible micropore structure and accordingly a micropore volume $\left(V_{\text {micro }}\right)$ of $0.11 \mathrm{~cm}^{3} \mathrm{~g}^{-1}$. Notably, also the uptake at $p / p_{0}>0.1$ increased and the mesopore (external) surface area amounted to $52 \mathrm{~m}^{2} \mathrm{~g}^{-1}$ (C-P-H). This development was more closely examined by low-pressure high-resolution Ar adsorption. Figs. S2a and b display the corresponding isotherms, whereas Fig. 4a shows the cumulative pore volume as a function of the pore size. The parent zeolite (C-P) did not exhibit any contribution in the $0.3-10 \mathrm{~nm}$ range, while the activated sample (C-P-H) displays a pronounced uptake around $0.4 \mathrm{~nm}$ and at $c a .3 \mathrm{~nm}$. The $0.4 \mathrm{~nm}$ contribution corresponds to the micropores, whereas the one at $3 \mathrm{~nm}$ is tentatively attributed to defects in the crystals caused

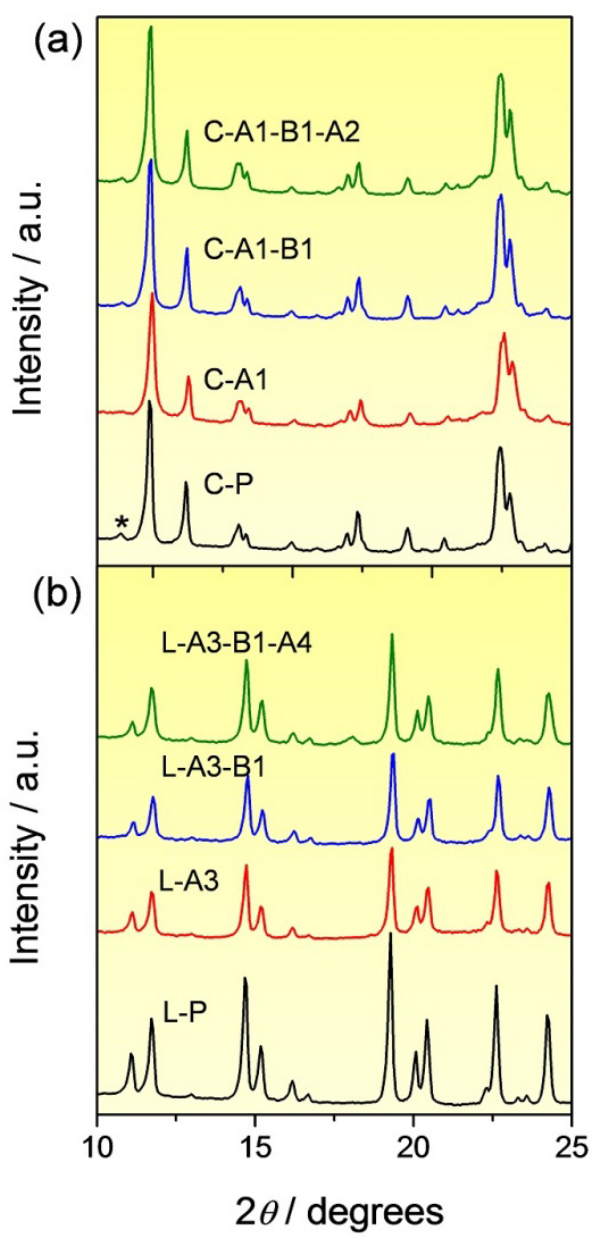

Figure 1. X-ray diffraction patterns of (a) clinoptilolite and (b) L zeolites. The asterisk in (a) indicates a minor phlogopite impurity.

by a partial condensation of Brønsted acid hydroxyls during calcination. ${ }^{34}$

The parent clinoptilolite was subjected to a large number of individual and sequential acid and base treatments resulting into the solids summarized in Tables $\mathbf{S}_{\mathbf{1}}-\mathbf{S}_{\mathbf{4}}$. For conciseness, discussion is focused on the properties of a number of key samples (Table 2). First, the influence of a direct base treatment was examined by variation of the molarity of the sodium hydroxide solution (o.2-1 M, Fig. 5a, and Table S2). The high solid yields and similar porous properties to the parent zeolite are clear signs that direct base treatment of clinoptilolite is inefficient. Next, the parent zeolite was subjected to a number of acid treatments in aqueous $\mathrm{HCl}$ (Table $\mathbf{S}_{\mathbf{3}}$ and Figs. $5 \mathbf{b}, \mathbf{c}$ ), aimed at framework dealumination to enable mesopore formation by a following base treatment. The $\mathrm{HCl}$ concentration varied between 1-2 $\mathrm{M}$, i.e. the optimal range established by Barrer and Makki. ${ }^{26}$ Unlike in the latter work, the solids yields, compositions, and porous properties in Fig. $\mathbf{5} \mathbf{b}$ evidenced minor variation as a function of the applied $\mathrm{HCl}$ concentration. Since a superior $\mathrm{Al}$ extraction can be reached by stepwise dealumination, ${ }^{27}$ the $1 \mathrm{M}$ 


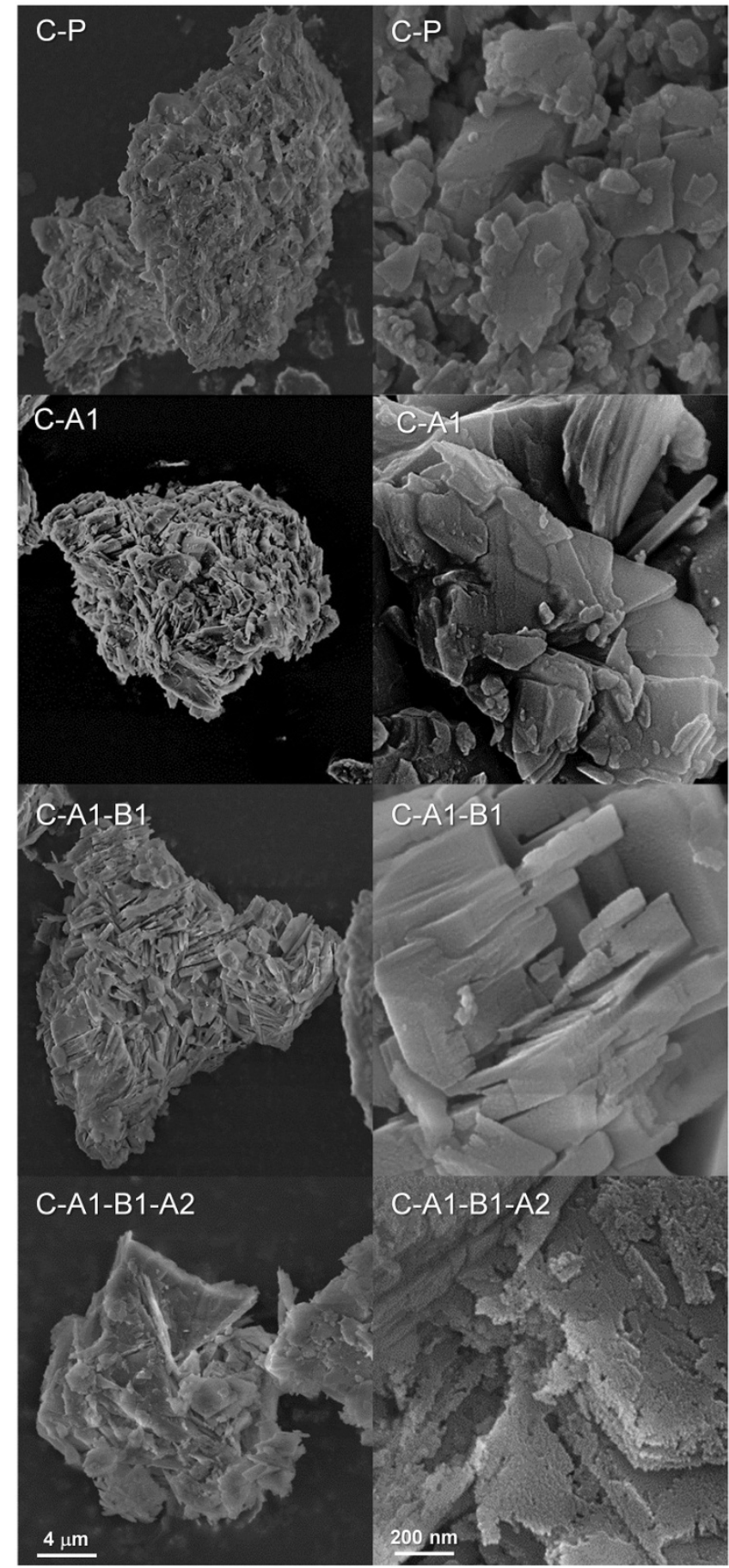

Figure 2. Scanning electron micrographs of clinoptilolite zeolites. The magnification of all images on the right, and all images on the left, is the same.

times. Fig. 5c shows a lower overall yield and higher mesopore surface and volume resulted. In line with the obtained yields, elemental analysis evidenced the value of the step-wise dealumination: whereas varying the $\mathrm{HCl}$ concentrations yielded similar $\mathrm{Si} / \mathrm{Al}$ ratios (ca. 8), the stepwise dealumination increased the $\mathrm{Si} / \mathrm{Al}$ ratio to over 10. In addition to the $\mathrm{Al}$ removal, the resulting solids dis- played micropore volumes of $0.08-0.13 \mathrm{~cm}^{3} \mathrm{~g}^{-1}$ due to the concomitant proton ion exchange (Tables 2 and $\mathbf{S}_{\mathbf{3}}$ ).

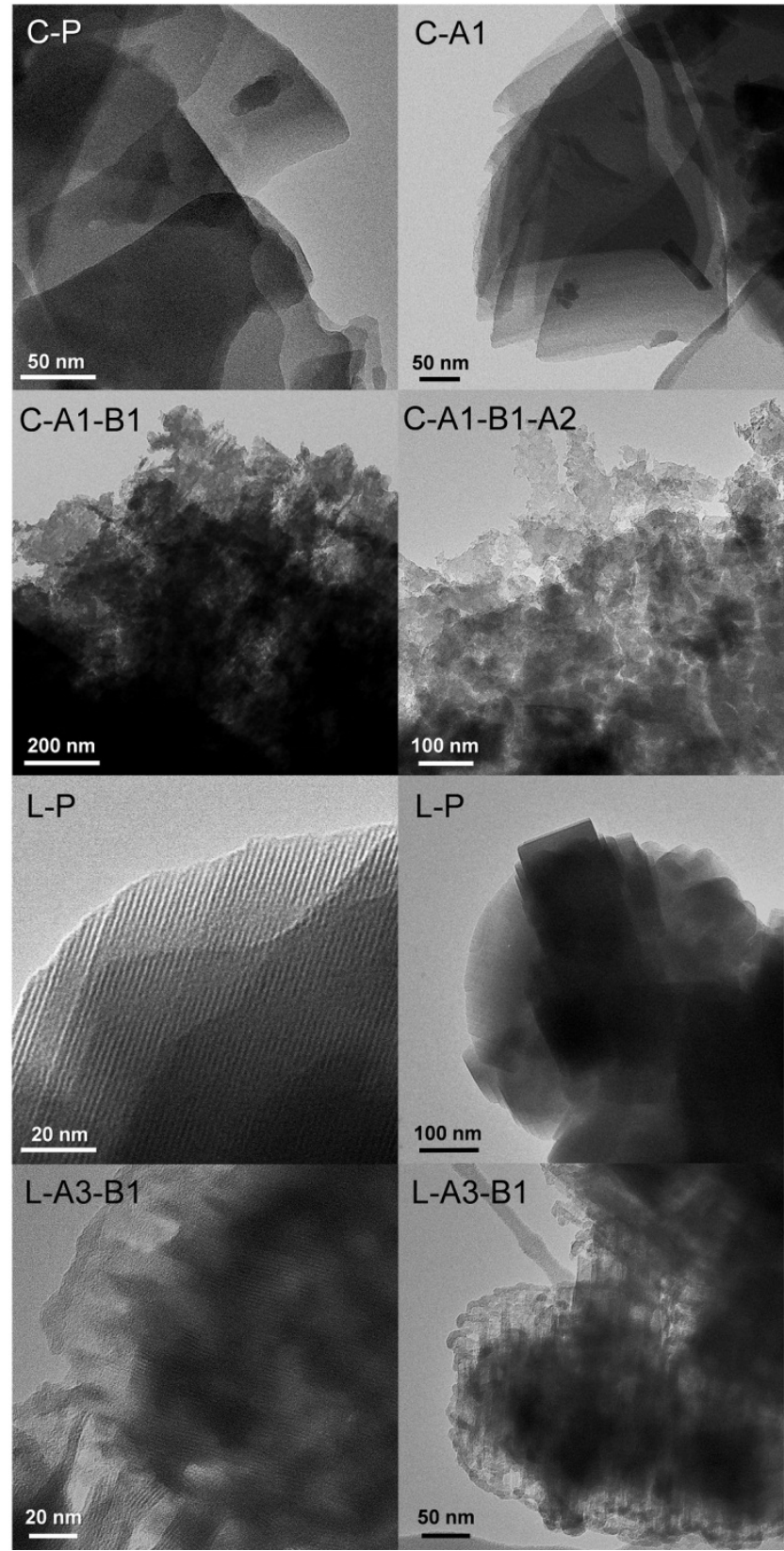

Figure 3. Transmission electron micrographs of clinoptilolite and L zeolites.

After the dealumination sequence, a standard sequential base treatment ('B1') was executed (Tables 2 and $\mathbf{S}_{4}$, and Figs. 6a,b). In contrast to the direct desilication, the base treatments after the acid treatments induced a substantial dissolution, attesting to the lower $\mathrm{Al}$ content. The yields showed a plateau at distinct values; $c a$. $70 \%$ for in case of varying the $\mathrm{HCl}$ concentration, and ca. 55\% for the stepwise dealumination. Assuming a preferential Si leaching (vide infra) and taking the $\mathrm{Si} / \mathrm{Al}$ ratios of the dealuminated zeolites into account (Fig. 5b,c), it can be deduced that zeolite dissolution by base treatment is hampered at a critical ratio, i.e. in the range of 6-8. Similar observations were made regarding acid and base-treated $\mathrm{Y}$ zeo 

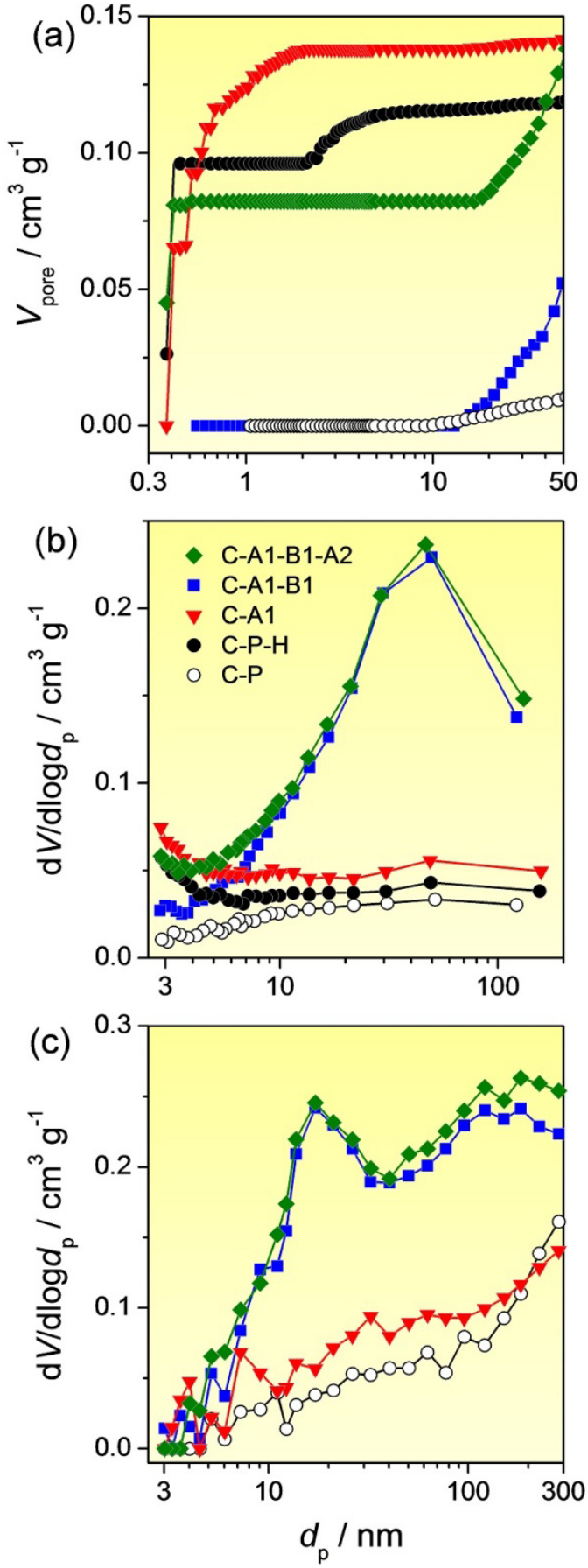

Figure 4. Porosity levels of clinoptilolite zeolites. (a) Cumulative pore volume ( $\left.V_{\text {pore }}\right)$ as a function of pore size $\left(d_{\mathrm{p}}\right)$ determined by Ar adsorption. (b,c) Pore size distributions derived from $\mathrm{N}_{2}$ adsorption or $\mathrm{Hg}$ intrusion, respectively.

lites, ${ }^{21}$ where a critical $\mathrm{Si} / \mathrm{Al}$ ratio of 3-4 was identified. We anticipate this ratio to be higher for the clinoptilolite zeolite due to its the smaller micropore size. The base treatment sprouted similar mesopore surface areas $\left(S_{\text {meso }}\right)$ compared to the acid-treated samples. However, the mesopore volumes $\left(V_{\text {meso }}\right)$ were up to 3 times higher (Figs. 6a,b). Optimization of the $\mathrm{NaOH}$ concentration, performed on sample $A_{1}$, evidenced that the highest $S_{\text {meso }}$ surface area was obtained at a milder concentration (o.1 $\mathrm{M} \mathrm{NaOH}$ ), while the highest mesopore volumes were obtained at $[\mathrm{NaOH}] \geq 0.2 \mathrm{M}$ (Fig. 6c). After base treatment, the concomitant $\mathrm{Na}^{+}$-ion exchange set the micropore volume almost to zero. The latter could be restored by a consequent $\mathrm{NH}_{4}$-exchange followed by calcination (C-A1-B1-H, Table 2).

A final acid treatment was performed to evaluate the influence of the position of the dealumination step in the overall modification sequence. The resulting sample (CA1-B1-A2) featured a $V_{\text {meso }}\left(0.32 \mathrm{~cm}^{3} \mathrm{~g}^{-1}\right)$ and $S_{\text {meso }}$ of over 6 times that of C-P (Table 2). The physico-chemical properties of $\mathrm{C}-\mathrm{A}_{1}-\mathrm{B}_{1}-\mathrm{A}_{2}$ and the other key samples are discussed in greater detail in Section 3.2.

\subsection{Extended characterization of clinoptilolite}

Porosity and morphology: Ar adsorption evidenced that, whereas sample C-P-H displayed contributions of 2-4 nm in size, C-Al comprised micropores in the size range of $0.5-2 \mathrm{~nm}$. Alternatively, the base-treated samples (C-A1$\mathrm{B} 1$, and $\mathrm{C}-\mathrm{A}_{1}-\mathrm{B}_{1}-\mathrm{A}_{2}$ ) featured mesopores $>10 \mathrm{~nm}$ (Fig. 4a). Since the pores of C-P-H and C-Ar are in the range of 0.5$4 \mathrm{~nm}$, the micropore volumes obtained by the $t$-plot method (applied to the $\mathrm{N}_{2}$ adsorption isotherm) should not only account for the intrinsic micropores. Close inspection of the cumulative uptake at pore sizes typical to the intrinsic pores (up to $0.5 \mathrm{~nm}$ ), reveals that C-P-H comprises the highest micropore volume $\left(V_{\text {micro, }} \mathrm{Ar}=\right.$ $0.10 \mathrm{~cm}^{3} \mathrm{~g}^{-1}$ ) (Table 2). The sequential acid treatments (C$\mathrm{Al}$ ) reduced this volume to $0.07 \mathrm{~cm}^{3} \mathrm{~g}^{-1}$, whereas the subsequent base treatment and dealumination (C-A1-B1-A2) displayed a volume of $c a .0 .08 \mathrm{~cm}^{3} \mathrm{~g}^{-1}$. The relative low intrinsic micropore volume of C-A 1 may be explained by the presence of amorphous species. Through subsequent base treatment, these are removed and the micropore volume is partially restored, relating well with the lower crystallinity evidenced for C-A1 (Fig. 1a). $\mathrm{N}_{2}$ isotherms reveal that whereas the dealuminated zeolite displayed only minor changes compared to $\mathrm{C}-\mathrm{P}-\mathrm{H}$, the samples $\mathrm{C}$ $\mathrm{A}_{1}-\mathrm{B}_{1}$ and $\mathrm{C}-\mathrm{A}_{1}-\mathrm{B} 1-\mathrm{A}_{2}$ displayed strongly enhanced uptake at $p / p_{0}>0.8$ (Fig. S1). Accordingly, agreeing well with $\mathrm{Ar}$ adsorption, the $\mathrm{BJH}$ mesopore size distribution displayed that the base-treated samples featured large contributions centered at sizes $>10 \mathrm{~nm}$ (Fig. $\mathbf{4} \mathbf{b}$ ). The large mesopores, although giving rise to modest external surfaces, displayed mesopore volumes up to 3 -fold that of C-P-H (Table 2).

$\mathrm{Hg}$ intrusion was performed to assess the mesoporosity and macroporosity in greater detail. The intrusion curves (Fig. S5) and related pore size distributions (Fig. 4c) demonstrate that C-Ar displays a similar meso- and macroporosity compared to C-P. Both samples displayed intrusion most pronounced in the 1-10o bar range, and a total intrusion volume of $c a .0 .7 \mathrm{~cm}^{3} \mathrm{~g}^{-1}$ was evidenced. Conversely, samples $\mathrm{C}-\mathrm{A}_{1}-\mathrm{B}_{1}$ and $\mathrm{C}-\mathrm{A}_{1}-\mathrm{B}_{1}-\mathrm{A}_{2}$ evidenced a strongly enhanced uptake in the range $1-1000$ bar and yielded a nearly doubled intrusion volume $\left(1.2 \mathrm{~cm}^{3} \mathrm{~g}^{-1}\right)$. In agreement with $\mathrm{N}_{2}$ and $\mathrm{Ar}$ adsorption (Figs. 4a,b), the pore size distributions display the presence of substantial mesoporosity in the range $10-300 \mathrm{~nm}$. SEM confirmed the 
(a)

(b)

(c)

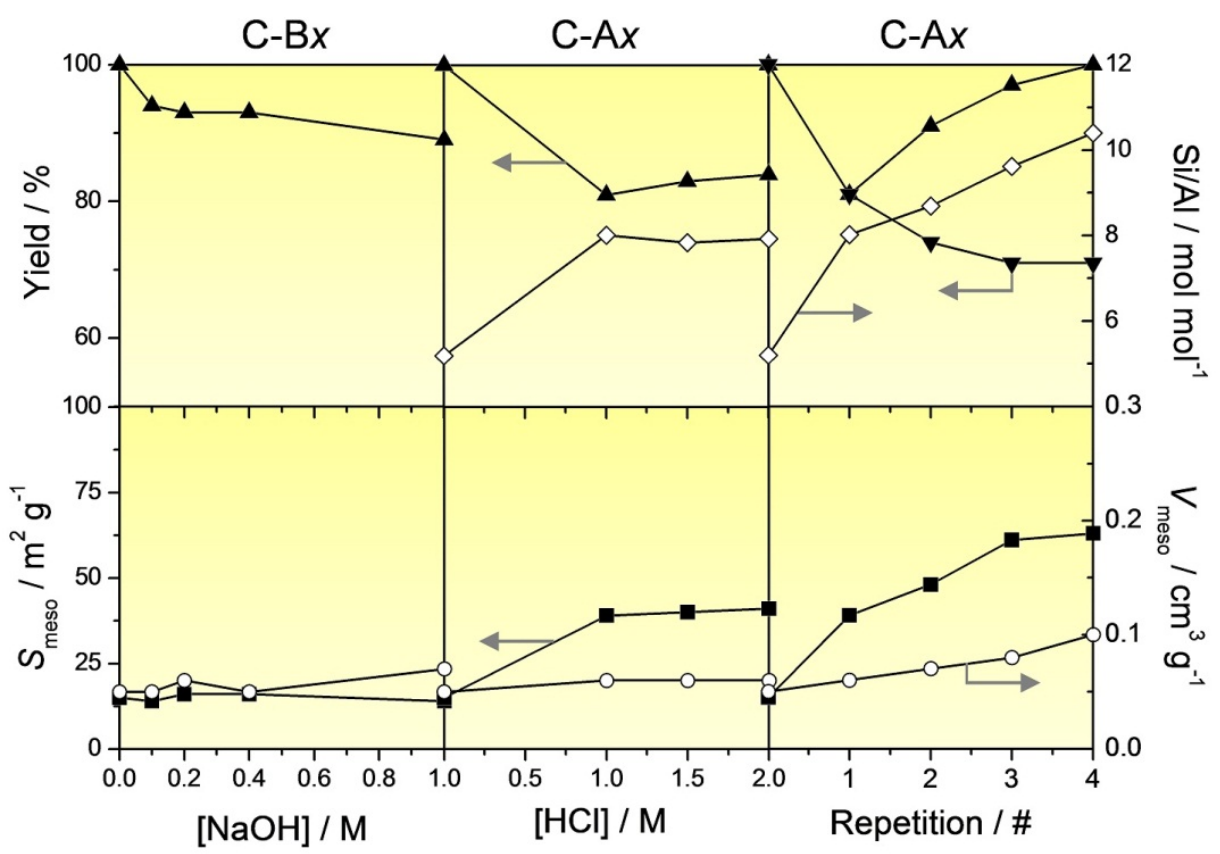

Figure 5. Individual $(\boldsymbol{\Delta})$ and overall $(\boldsymbol{\nabla})$ yield, composition $(\diamond)$, mesopore surface $\left(S_{\text {meso, }} \boldsymbol{\nabla}\right)$, and mesopore volume $\left(V_{\text {meso, }}, \circ\right)$ of solids obtained by subjecting the parent clinoptilolite zeolite to (a) individual $\mathrm{NaOH}$, (b) individual $\mathrm{HCl}$, or (c) repetitive $1 \mathrm{M}$ $\mathrm{HCl}$ treatments. The parent zeolite is represented at o $\mathrm{M}(\mathrm{a}, \mathrm{b})$ or o repetitions $(\mathrm{c})$. The corresponding sample codes are indicated directly above the graphs.

(a)

(b)

(c)

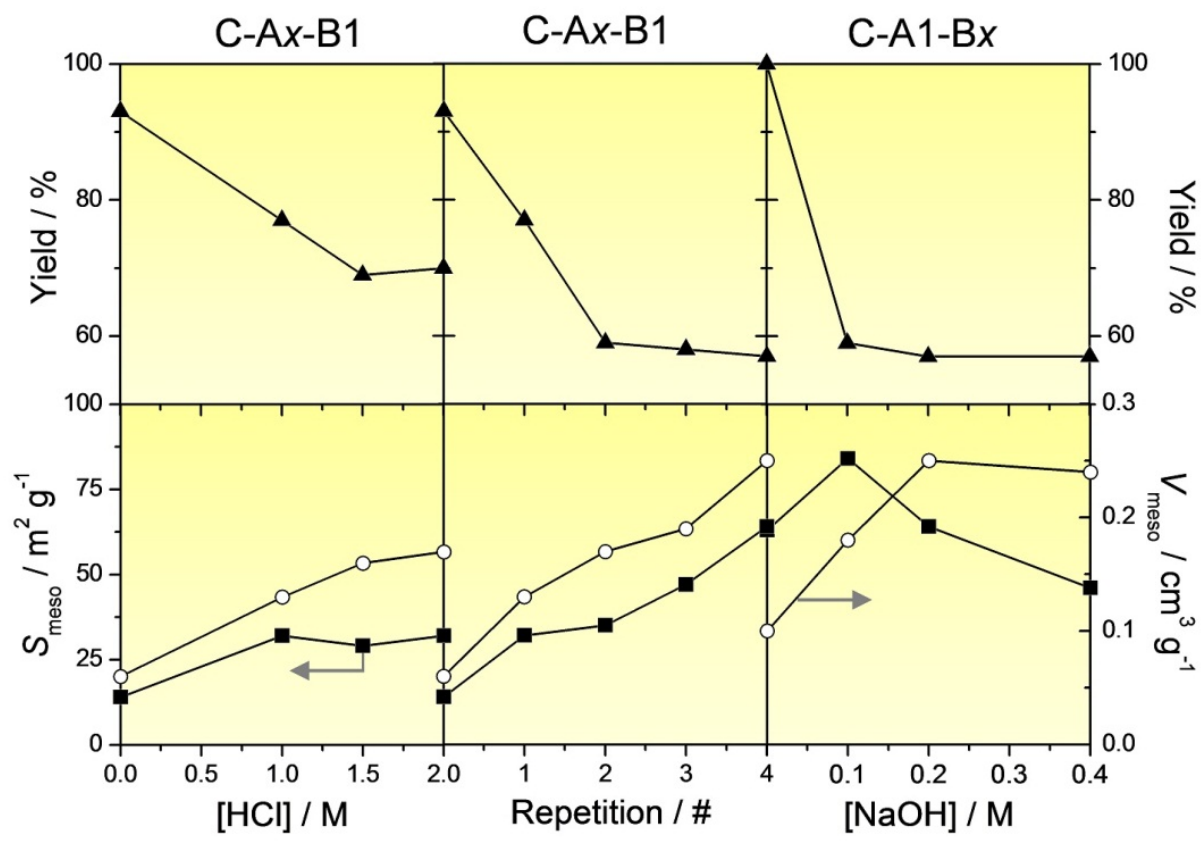

Figure 6. Individual yield $(\boldsymbol{\Delta})$, mesopore surface $\left(S_{\text {meso }}, \boldsymbol{\square}\right)$, and mesopore volume $\left(V_{\text {meso }}, \circ\right)$ of clinoptilolite zeolites subjected to tandem acid and base treatments. (a, b) Yield and mesoporosity after subjecting the acid-treated samples in Fig. $\mathbf{5}^{\mathbf{b}, \mathbf{c}}$ to a standard base treatment (at $0.2 \mathrm{M} \mathrm{NaOH}$, i.e. conditions of 'B1' in Table 1). (c) Yield and porosity resulting from exposure of the 4times sequentially $\mathrm{HCl}$-treated sample $\left(\mathrm{C}-\mathrm{A}_{1}\right)$ to alkaline solutions of various $\mathrm{NaOH}$ concentrations. The corresponding sample codes are indicated directly above the graphs. 
Table 2. Yields and properties of clinoptilolite zeolites

\begin{tabular}{|c|c|c|c|c|c|c|c|c|c|}
\hline Sample & $\begin{array}{l}\text { Yield }^{a} \\
(\%)\end{array}$ & $\begin{array}{c}\mathrm{Si} / \mathrm{Al}_{\text {bulk }}{ }^{\mathrm{b}} \\
\left(\mathrm{mol} \mathrm{mol}^{-1}\right)\end{array}$ & $\begin{array}{l}\mathrm{Si} / \mathrm{Al}_{\text {surface }}{ }^{\mathrm{c}} \\
\left(\mathrm{mol} \mathrm{mol}^{-1}\right)\end{array}$ & $\begin{array}{l}\text { Acidity } \\
\text { (\%) }\end{array}$ & $\begin{array}{l}V_{\text {micro }} \mathrm{e} \\
\left(\mathrm{cm}^{3} \mathrm{~g}^{-1}\right)\end{array}$ & $\begin{array}{l}V_{\text {micro, } \mathrm{Ar}^{\mathrm{f}}} \\
\left(\mathrm{cm}^{3} \mathrm{~g}^{-1}\right)\end{array}$ & $\begin{array}{c}V_{\text {pore }^{\mathrm{g}}} \\
\left(\mathrm{cm}^{3} \mathrm{~g}^{-1}\right)\end{array}$ & $\begin{array}{c}V_{\text {meso }^{\mathrm{h}}} \\
\left(\mathrm{cm}^{3} \mathrm{~g}^{-1}\right)\end{array}$ & $\begin{array}{c}S_{\text {meso }}{ }^{\mathrm{e}} \\
\left(\mathrm{m}^{2} \mathrm{~g}^{-1}\right)\end{array}$ \\
\hline C-P & - & 5.2 & 5.5 & - & o & o & 0.05 & 0.05 & 15 \\
\hline C-P-H & - & - & - & 100 & 0.11 & 0.10 & 0.19 & 0.08 & 52 \\
\hline$C-A_{1}$ & 71 & 10.4 & 40.3 & 73 & 0.13 & 0.07 & 0.23 & 0.10 & 63 \\
\hline C-A1-B1 & $57(41)^{\mathrm{i}}$ & 6.3 & 7.6 & - & 0.02 & o & 0.25 & 0.23 & 64 \\
\hline C-A1-B1-H & - & - & - & 103 & 0.11 & - & 0.37 & 0.26 & 85 \\
\hline C-A1-B1-A2 & 89 (37) & 7.6 & 19.1 & 75 & 0.10 & 0.08 & 0.42 & 0.32 & 103 \\
\hline
\end{tabular}

a Grams of solid after treatment per gram of starting material. ${ }^{\text {IICP-OES. }}{ }^{c X P S}{ }^{\mathrm{d} A m m o n i a}$ uptake relative to C-P-H. ${ }^{e} t$-plot method. ${ }^{\mathrm{f} C}$ umulative volume of pores $\leq 5 \AA$ determined by Ar adsorption. ${ }^{\mathrm{g} V o l u m e}$ adsorbed at $p / p_{\mathrm{o}}=0.99$. ${ }^{\mathrm{h}} V_{\text {meso }}=V_{\text {pore }}{ } V_{\text {micro }}$. iValues in parentheses indicate the overall yield after treatment.

minor morphological differences between C-P and C-A1. However, $\mathrm{C}-\mathrm{A}_{1}-\mathrm{B}_{1}$ and $\mathrm{C}-\mathrm{A}_{1}-\mathrm{B}_{1}-\mathrm{A}_{2}$ displayed much larger crystal sizes and more intercrystalline porosity (Fig. 2). This may be due to the selective dealumination of the smaller crystals, which, in turn, leads to their preferential dissolution (vide infra). TEM evidences that, whereas the crystals of $\mathrm{C}-\mathrm{P}$ and $\mathrm{C}-\mathrm{A} 1$ appear rather similar, samples $\mathrm{C}$ $\mathrm{A}_{1}-\mathrm{B}_{1}$ and $\mathrm{C}-\mathrm{A}_{1}-\mathrm{B}_{1}-\mathrm{A}_{2}$ display heavily corroded crystals, that should possess both inter- and intracrystalline mesoporosity (Fig. 3). The appearance and type of mesoporosity of the alkaline-treated crystals resemble base-treated ferrierite platelets ${ }^{35}$ and ZSM-22 nanorods. ${ }^{36}$

Composition, structure, and acidity: Elemental analysis was performed to get a better insight in the compositional changes during the treatment sequence (Table 2). Whereas the four dealumination treatments doubled the bulk Si/Al from 5.2 (C-P) to 10.4 (C-A1), the subsequent base treatment reduced the $\mathrm{Si} / \mathrm{Al}$ ratio back to 6.3 (C-A1$\mathrm{B} 1)$. This value, in combination with the $57 \%$ yield, enables to conclude that the alkaline leaching induced a preferential Si removal from the solid. Accordingly, we expected a strong reduction of the micropore volume due to the deposition of $\mathrm{Al}$ debris. However, sample $\mathrm{C}-\mathrm{A}_{1}-\mathrm{B}_{1}-$ $\mathrm{H}$ displayed a micropore volume similar to $\mathrm{C}-\mathrm{P}-\mathrm{H}$, suggesting minimal realumination. The relative abundance of $\mathrm{Si}$ and $\mathrm{Al}$ on the surface was probed using XPS (Table 2). The results show that, whereas the surface and bulk compositions in the parent zeolite were similar, the dealuminated sample displayed a much higher surface (40.3) than bulk Si/Al ratio (10.4), indicating a preferential surface dealumination by the acid treatment. After subsequent alkaline treatment the aluminum gradient was mostly absent, while it partially restored after the final acid treatment. The influence of aluminum gradients in the post-synthetic sequence is discussed in detail in Section 3.4.

The coordination of $\mathrm{Al}$ and $\mathrm{Si}$ atoms in the clinoptilolite zeolites was studied by ${ }^{27} \mathrm{Al}$ and ${ }^{29} \mathrm{Si}$ MAS NMR, respectively. The aluminum spectra reveal that during the treatments the bulk of the $\mathrm{Al}$ remained in tetrahedral (lattice) positions (Fig. $\mathbf{7 a}, \mathbf{b})$. Nevertheless, after the acid treatments $\left(\mathrm{C}-\mathrm{A}_{1}\right.$ and $\left.\mathrm{C}-\mathrm{A}_{1}-\mathrm{B}_{1}-\mathrm{A}_{2}\right)$, minor contributions around o ppm, i.e. those related to octahedral, extraframework species, occurred. The total intensity of the spectra relates well with the $\mathrm{Al}$ content in the samples. The shift of the framework aluminum of the acid-treated samples decreases from $56 \mathrm{ppm}$ (C-P) to $54 \mathrm{ppm}$ (C-A1 and $\mathrm{C}-\mathrm{A}_{1}-\mathrm{B}_{1}-\mathrm{A}_{2}$, (Fig. 7a), indicating a slightly different environment of the aluminum. ${ }^{29}$ Si MAS NMR displayed a pronounced effect of the sequential dealumination treatments $\left(C-A_{1}\right)$, that is, the $\mathrm{Q}_{4}$ contributions of $\mathrm{Si}(\mathrm{oAl})(-112$ $\mathrm{ppm})$ increased in intensity, whereas the $\mathrm{Si}(2 \mathrm{Al})(-101$ ppm) decreased (Fig. 9c). After base treatment (C-A1-B1) this trend is reversed, revealing, in line with the ${ }^{27} \mathrm{Al}$ MAS NMR, a coordination similar to the parent zeolite. The final acid treatment ( $\mathrm{C}-\mathrm{A} 1-\mathrm{B} 1-\mathrm{A} 2)$ had a similar, though less severe, effect as the first sequential dealuminations.

The acidity of the clinoptilolite samples was investigated by $\mathrm{NH}_{3}$-TPD and infrared spectroscopy in the $\mathrm{OH}$ stretching region. The $\mathrm{NH}_{3}$-TPD profile of the activated parent zeolite (C-P-H) displayed two contributions (Fig. 8a). A minor contribution around $290^{\circ} \mathrm{C}$, related to weakly adsorbed ammonia, and a larger one centered around $550^{\circ} \mathrm{C}$, attributed to ammonia adsorbed on strong acid sites. $^{29}$ For reference, a $\mathrm{NH}_{3}$-TPD profile of a ZSM-5 $(\mathrm{Si} / \mathrm{Al}=15)$ was measured. The latter zeolite evidenced a total acidity of $80 \%$ compared to $\mathrm{C}-\mathrm{P}-\mathrm{H}$, while its $\mathrm{Al}$ content was roughly a third. This suggests that the total acidity of $\mathrm{C}-\mathrm{P}-\mathrm{H}$ is about half of what can be expected based on its Al content. A similar observation was made for mordenite, ${ }^{37}$ where only about $50 \%$ of the acid sites could be probed by $\mathrm{NH}_{3}$-TPD. We attribute this relatively low total acidity to an incomplete $\mathrm{NH}_{4}{ }^{+}$ion-exchange during activation. ${ }^{8}$ Upon post-synthetic modification of the clinoptilolite zeolite, the position of the contributions in the $\mathrm{NH}_{3}$-profiles were similar, while the total acidities varied in line with the observed compositional changes (Table 2). However, the differences in Al content (up to 50\%) largely exceeded the variation in the total acidity (up to $27 \%$ ). Possibly, the influence of the post-synthetic 


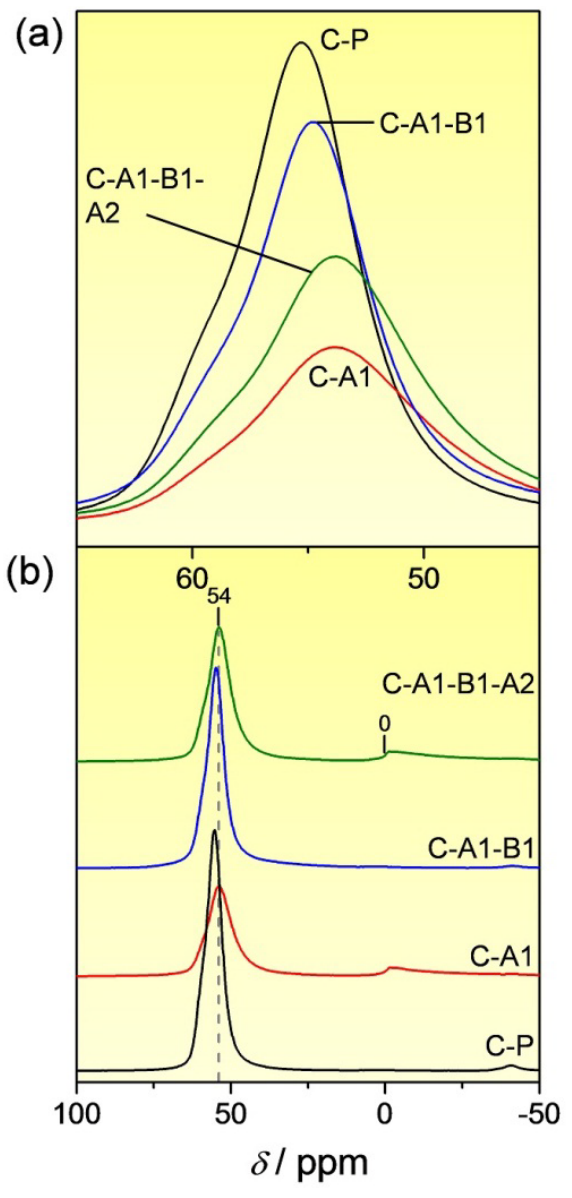

(c)

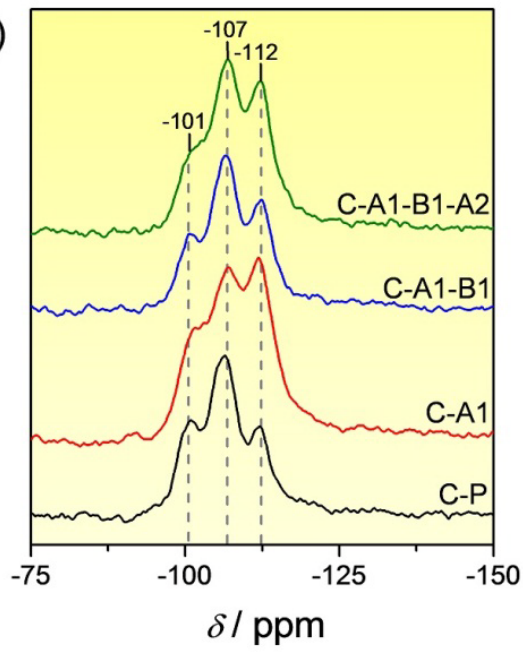

Figure 7. (a,b) ${ }^{27} \mathrm{Al}$ and (c) ${ }^{29} \mathrm{Si}$ MAS NMR of clinoptilolite zeolites.

modifications on the total acidity is masked by an alteration of the ion-exchange efficiency (see also Section 3.5).

Infrared spectroscopy in the $\mathrm{OH}$-stretching region revealed the typical finger print spectrum of activated clinoptilolite (Fig. 8b). A small band around $3743 \mathrm{~cm}^{-1}$ was evidenced, attributed to lattice terminating silanols groups, and the main band centered at $3600 \mathrm{~cm}^{-1}$, relating to (Brønsted) acidic hydroxyls. ${ }^{34}$ After the acid treatments $(\mathrm{C}-\mathrm{Al})$, the bands became indiscernible, which could be linked to the presence of crystal defects combined with
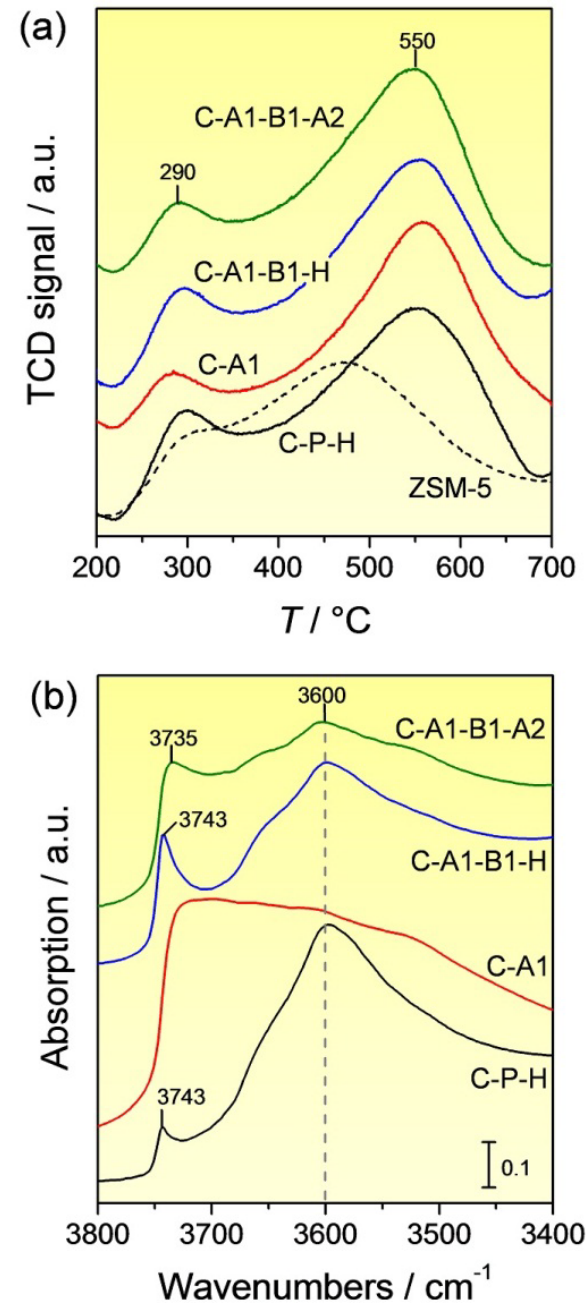

Figure 8. (a) $\mathrm{NH}_{3}$-TPD profiles and (b) infrared spectra in the $\mathrm{OH}$ stretching region of clinoptilolite and ZSM-5 zeolites.

amorphous debris, broadening the contributions. ${ }^{39}$ After base treatment $\left(\mathrm{C}-\mathrm{A}_{1}-\mathrm{B}_{1}-\mathrm{H}\right)$, the spectrum became similar to that of the parent, clearly showing the bands at 3743 and $3600 \mathrm{~cm}^{-1}$. Whereas the former band is increased in intensity due to the enhanced external surface, the latter was reduced due to the lower $\mathrm{Al}$ content. Like the initial dealuminations, the final acid treatment (C-A1-B1A2) led to broadening of the bands.

\subsection{Synthesis of hierarchical $L$}

The synthetic L zeolite (LTL topology) features unidirectional 12-ring micropores of a diameter of $0.71 \mathrm{~nm}$. This zeolite can be synthesized with a Si/Al ratio of $\mathrm{ca}$. 3, rendering it similar to zeolite Y. ${ }^{3}$ Mesoporous L has been prepared by bottom-up strategies. However, the required modified zeolite syntheses, involving costly carbon templates, resulted in poorly crystalline materials. ${ }^{40,41}$ In addition, their performance in catalytic conversions remains unclear. Unlike for zeolite $\mathrm{Y}^{21,42}$ little is known about the possibilities to tune $\mathrm{L}$ by post-synthetic modifications. Thus far, only dealumination treatments, aimed at the stabilization of the framework, have been reported.33,43 
Nevertheless, these treatments concomitantly reduced crystallinity and the micropore volume strongly. ${ }^{43}$

Based on the similarities of the micropore size and the $\mathrm{Si} / \mathrm{Al}$ ratio, the approach established for $\mathrm{Y}^{21}$ was applied to L. Accordingly, the ammonium form of the zeolite was first treated with ammonium hexafluorosilicate to increase the $\mathrm{Si} / \mathrm{Al}$ ratio from $2.9(\mathrm{~L}-\mathrm{P})$ to $c a .6\left(\mathrm{~L}-\mathrm{A}_{3}\right),{ }^{43}$ to facilitate dissolution by subsequent base treatment. After the base leaching ( $\left.\mathrm{L}_{-} \mathrm{A}_{3}-\mathrm{B}_{1}\right)$, an acid wash was performed using aqueous $\mathrm{Na}_{2} \mathrm{H}_{2}$ EDTA (L-A3-B1-A4). The yields of these treatments and the porous properties of the resulting solids are summarized in Table 3, whereas the XRD patterns, electron micrographs, and nitrogen isotherms are presented in Figs. 1,3, and $\mathbf{S}$, respectively. The parent L zeolite featured an impurity-free diffraction pattern typical of the LTL framework. Nitrogen adsorption and TEM evidenced its mostly microporous character. In addition, TEM showed the agglomerated nature of the crystals.

Table 3. Yields and properties of $L$ zeolites

\begin{tabular}{lccccc} 
Sample & $\begin{array}{c}\text { Yield }^{\mathrm{a}} \\
(\%)\end{array}$ & $\begin{array}{c}V_{\text {micro }}{ }^{\mathrm{b}} \\
\left(\mathrm{cm}^{3} \mathrm{~g}^{-1}\right)\end{array}$ & $\begin{array}{c}V_{\text {pore }^{\mathrm{c}}} \\
\left(\mathrm{cm}^{3} \mathrm{~g}^{-1}\right)\end{array}$ & $\begin{array}{c}V_{\text {meso }^{\mathrm{d}}} \\
\left(\mathrm{cm}^{3} \mathrm{~g}^{-1}\right)\end{array}$ & $\begin{array}{c}S_{\text {meso }}{ }^{\mathrm{b}} \\
\left(\mathrm{m}^{2} \mathrm{~g}^{-1}\right)\end{array}$ \\
L-P & - & 0.15 & 0.27 & 0.12 & 45 \\
L-A3 & 90 & 0.07 & 0.31 & 0.24 & 70 \\
L-A3-B1 & $\begin{array}{c}72 \\
(65)\end{array}$ & 0.14 & 0.49 & 0.35 & 135 \\
L-A3-B1- & $\begin{array}{c}95 \\
\text { A4 }\end{array}$ & 0.12 & 0.53 & 0.41 & 123 \\
\hline
\end{tabular}

${ }^{a}$ Grams of solid after treatment per gram of starting material. ${ }^{\mathrm{b}} t$-plot method. ${ }^{c}$ Volume adsorbed at $p / p_{\mathrm{o}}=0.99 \cdot{ }^{\mathrm{d}} V_{\text {meso }}=$

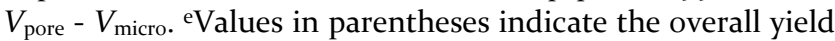
after treatment.

The yield of the dealumination treatment was relatively high (90\%), which is attributed to the substitution of $\mathrm{Si}$ atoms from the $\left(\mathrm{NH}_{4}\right)_{2} \mathrm{SiF}_{6}$ solution to the solid during $\mathrm{Al}$ extraction from the zeolite framework. 33 The crystallinity of $\mathrm{L}-\mathrm{A}_{3}$ was reduced to about $40 \%$ and, in line with previous observations, ${ }^{43}$ a strong reduction in the micropore volume was observed. Subsequently, whereas conventional direct desilication of the parent zeolite did not modify the solid in any way (data not shown), base treatment on the dealumination sample led to a substantial dissolution (72\% solid yield) and a 3-fold increase in the mesopore surface and volume ( $\left.\mathrm{L}_{-} \mathrm{A}_{3}-\mathrm{B}_{1}\right)$. Hence, sequential dealumination and desilication enables to prepare hierarchical $\mathrm{L}$ zeolites. Moreover, the base treatment completely restored the micropore volume, which should be due to the removal of amorphous matter formed during the dealumination treatment. This is supported by the disappearance of the broad peak around $21^{\circ} 2 \theta$, typical to amorphous silica (Fig. S4).39 This highlights the use of base treatments to clean up zeolitic structures after framework dealumination treatments. The final $\mathrm{Na}_{2} \mathrm{H}_{2}$ EDTA acid wash (L-A3-B1-A4) did not have a very large impact on the porosity of the sample, which is further discussed in Sec- tion 3.4. TEM showed that the nature of the secondary porosity is mostly of intracrystalline nature. However, because of the agglomerated nature of the sample, intercrystalline contributions cannot be excluded.

\subsection{Importance of framework dealumination in the post-synthetic sequence}

In the design of hierarchical zeolites by sequences of post-synthetic modifications, framework dealumination represents a crucial first step as its efficiency affects each of the following treatments. Thus far, the efficiency of the dealumination was mostly attested by the bulk $\mathrm{Si} / \mathrm{Al}$ ratio and the resulting enhanced dissolution by base treatment. However, the resulting $\mathrm{Al}$ distribution should also have a pronounced influence of on the efficiency of the subsequent base leaching. The latter is particularly relevant taking into account that the dealuminated clinoptilolite zeolite ( $\mathrm{C}-\mathrm{A} \mathbf{1})$ displayed a pronounced $\mathrm{Al}$ gradient (Table 2). In fact, Al gradients commonly occur after dealumination, depending on the properties of the parent zeolite (e.g. Al distribution, particle size, micropore structure) ${ }^{44}$ and the chemical nature of the aluminum extraction. ${ }^{45,46}$

The results in Sections 3.1-3.3 established that base treatment of the dealuminated clinoptilolite or L zeolites resulted in samples resembling strongly the parent zeolites in terms of crystallinity, composition, acidity, coordination, and microporosity. This is in clear contrast with other zeolites like ZSM-22, ${ }^{36} \mathrm{ZSM}-5,{ }^{47}$ and $\mathrm{Y},{ }^{21}$ in which the base-treated zeolites were distinctly different than the parent zeolites due to the deposition of substantial amounts of Al-rich debris. Subsequently, a surface dealumination using an acid wash (performed after alkaline leaching) was applied to restore part of the microporosity, crystallinity, and acidity. These differences should originate from the particular $\mathrm{Al}$ distributions in the zeolite directly prior to base treatment.

The influence of the $\mathrm{Al}$ distribution is conceptually illustrated in Fig. 9, where a post-synthetic protocol comprising out of framework dealumination, desilication, and surface dealumination is applied to two similar Al-rich zeolite crystals (a and $\mathbf{e}$ ). Whereas both framework dealuminations remove $50 \%$ of the $\mathrm{Al}$ atoms, the resulting $\mathrm{Al}$ distributions are different: yielding either a crystal with a homogeneous distribution (b), or heterogeneous one with an Al-rich or an Al-depleted zone (f). Upon desilication of (b), a dissolution similar to what was postulated for ZSM- $5^{48}$ occurs, resulting into an efficient mesopore formation and the deposition of a surplus of realuminated species (c), which are removed by a subsequent surface dealumination (d). Conversely, when strong $\mathrm{Al}$ gradients are present, the base treatment has little effect on the Alrich parent-like part of the crystal. On the other hand, the Al-depleted part is completely unselectively dissolved, resulting in a much less efficient mesopore formation and limited realumination $(\mathbf{g})$. The latter also highlights why a subsequent surface dealumination (h) is unable to restore 


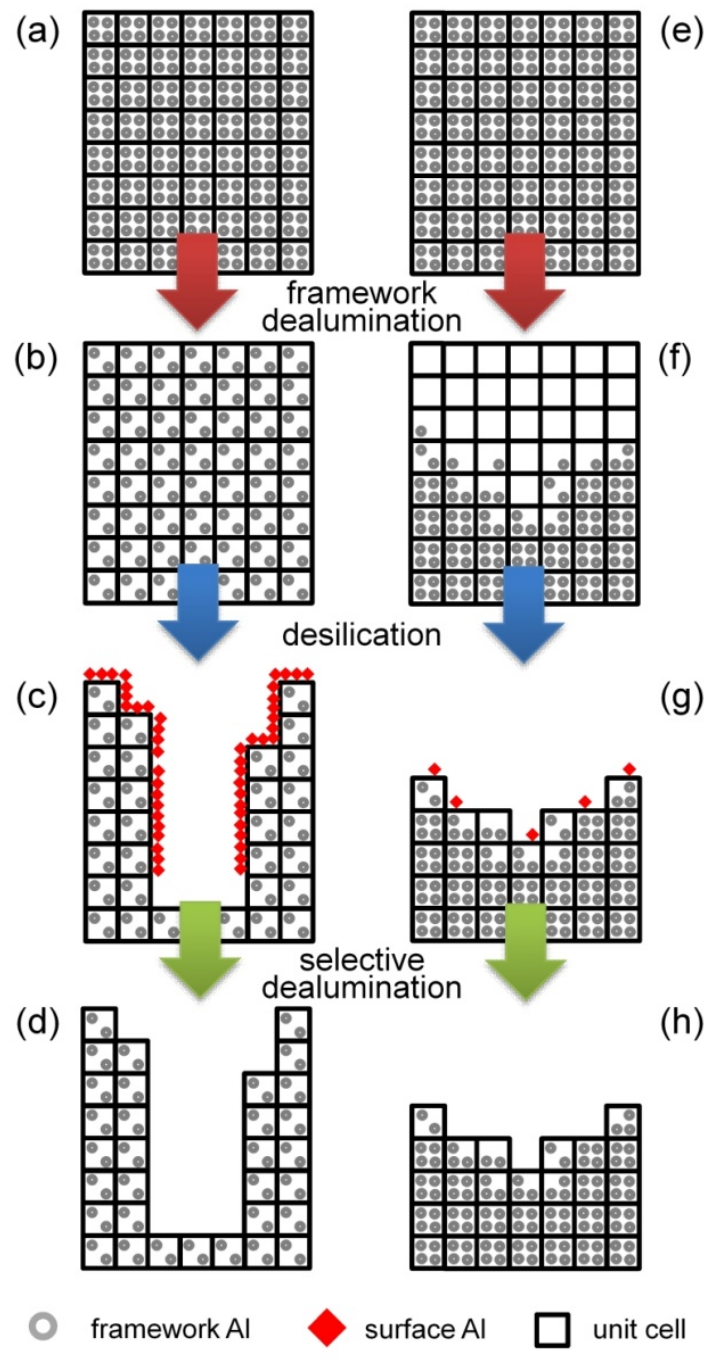

Figure 9. Schematic representation of two distinct postsynthetic acid-base-acid treatment sequences. A homogenous dealumination ( $a-b)$ leads to an efficient mesopore formation by desilication (b-c) and a surplus of surface aluminum species that need to be removed by a final selective dealumination (c-d). A framework dealumination that causes strong $\mathrm{Al}$ gradients (e-f) renders the subsequent desilication inefficient (f-g) and makes final selective dealumination redundant ( $\mathrm{g}-\mathrm{h})$.

the $\mathrm{Si} / \mathrm{Al}$ ratio obtained during framework dealumination (f).

The existence of different base leaching mechanisms relates well with the reported desilication efficiencies (DE), factoring the introduced external surface with the fraction of dissolved solid. ${ }^{36}$ For clinoptilolite, the mesopores formed were large and the resulting efficiency was very low $\left(\mathrm{DE}=0.8 \mathrm{~m}^{2} \mathrm{~g}^{-1} \%{ }^{-1}\right.$ for $\left.\mathrm{C}-\mathrm{Al}-\mathrm{Bl}\right)$. Also in the case of $\mathrm{L}$ zeolite, the base treatment yielded large pores and was subsequently not very efficient $\left(\mathrm{DE}=2.6 \mathrm{~m}^{2} \mathrm{~g}^{-1} \%{ }^{-1}\right.$ for $\mathrm{L}$ $\mathrm{A} 3-\mathrm{B} 1)$. Conversely, for zeolite $\mathrm{Y}$, the introduction of mesoporosity was more efficient $\left(\mathrm{DE}=6 \mathrm{~m}^{2} \mathrm{~g}^{-1} \%{ }^{-1}\right)$. ${ }^{21}$ Nevertheless, the efficiency in the case of $\mathrm{Y}$ was lower compared to its severely dealuminated USY $(\mathrm{Si} / \mathrm{Al}=30)$ counterpart. In the latter case a higher value $\left(\mathrm{DE}=10 \mathrm{~m}^{2} \mathrm{~g}^{-1} \%{ }^{-1}\right)$ was

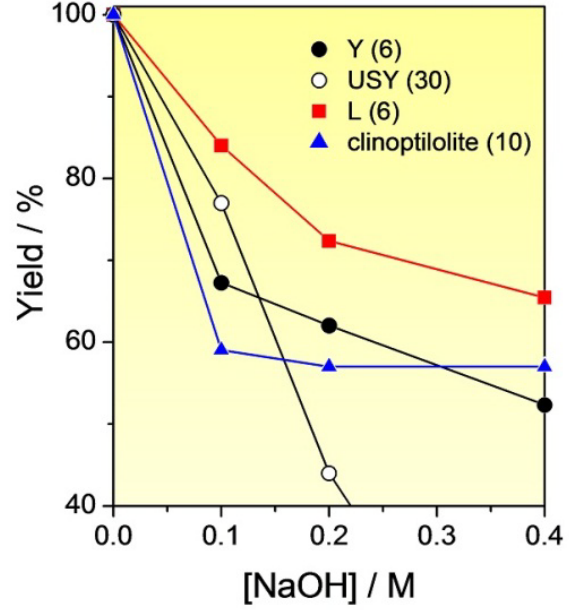

Figure 10. The solid yield as a function of the applied concentration of $\mathrm{NaOH}$ during the base treatment of various dealuminated zeolites. The value in parentheses highlights the (bulk) Si/Al ratio of the zeolite prior to base treatment. The yields for $Y$ and USY are from ref. 21.

attained, ${ }^{39}$ suggesting that also dealuminated zeolite $\mathrm{Y}$ contains $\mathrm{Al}$ gradients. This is corroborated by the fact that, like for clinoptilolite, the final acid wash of zeolite $\mathrm{Y}$ was not able to attain the $\mathrm{Si} / \mathrm{Al}$ ratio obtained after the initial framework dealumination $(\mathrm{Si} / \mathrm{Al}=4.2$ vs. 5.5, respectively). ${ }^{21}$ For clinoptilolite this is particularly evident, taking into account that the final acid treatment was rather severe, i.e. $1 \mathrm{M} \mathrm{HCl}$.

Another effect of the co-presence of intrinsic and Aldepleted zones in the zeolite crystal is the dissolution behavior as a function of the alkalinity of the applied $\mathrm{NaOH}$ solution (Fig. 10). Whereas for USY a near linear loss of solid vs. the $\mathrm{NaOH}$ concentration occurs, a steep initial loss of weight followed by a horizontal plateau is observed for L, Y, and (particularly pronounced) for clinoptilolite zeolites. The initial steep dissolution should relate to the facile dissolution of the Al-depleted part of the solids (top part of the crystal in Fig. 9f), while the plateau relates to the more inert intrinsic zeolite framework remaining (lower part in Fig. 9f). Likely, the better the distributions of the Al-depleted zones throughout the crystals, the more efficient subsequent mesopore formation by base leaching will be. In turn, these results highlight that irrespective to mesopore formation, base leaching represents a suitable method to probe efficiency of dealumination treatments.

3.5. Catalytic and adsorptive evaluation of hierarchical clinoptilolite and $\mathrm{L}$ zeolites

Clinoptilolite zeolites are commonly used as adsorbents to remove contaminants, e.g. heavy metals or organic dyes, from waste streams. ${ }^{1}$ Therefore, the performance of the clinoptilolite samples was evaluated in the adsorption of $\mathrm{Cu}^{2+}$ or methylene blue (MB) from aqueous solutions. Particularly, taking the bulky nature of methylene blue cations into account, the introduction of mesoporosity 
(a)

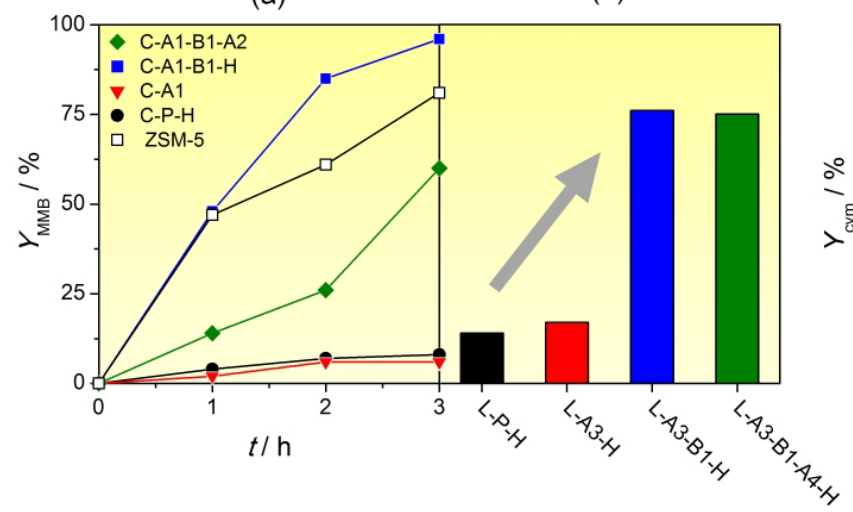

(c)

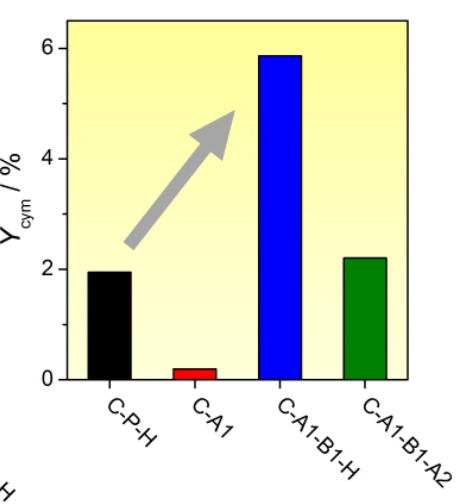

(d)

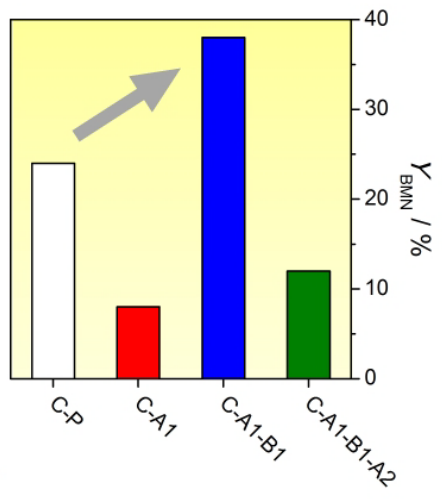

Figure 11. (a,b) The yield of (methyl)benzylbenzene $\left(Y_{\mathrm{MBB}}\right)$ in the alkylation of toluene $(\mathrm{T})$ with benzyl alcohol (BA) over clinoptilolite, ZSM-5, and L zeolites. (c) The yield of cymene ( $\left.Y_{\text {cym }}\right)$ over clinoptilolite zeolites in the alkylation of toluene with isopropyl alcohol (IPA). (d) The yield of benzylidenemalononitrile ( $\left.Y_{\text {BMN }}\right)$ in the Knoevenagel condensation of benzaldehyde (BAD) with malononitrile (MN) over clinoptilolite zeolites. Conditions: (a) $\mathrm{T}=180^{\circ} \mathrm{C}, \mathrm{T} / \mathrm{BA}=8 \mathrm{o}, W_{\text {cat }}=25 \mathrm{mg},(\mathrm{b}) \mathrm{T}=130^{\circ} \mathrm{C}, \mathrm{T} / \mathrm{BA}=8 \mathrm{o}$, $W_{\text {cat }}=25 \mathrm{mg}, t=0.5 \mathrm{~h}$, (c) $T=180^{\circ} \mathrm{C}, \mathrm{T} / \mathrm{IPA}=40, W_{\text {cat }}=50 \mathrm{mg}, t=20 \mathrm{~h},(\mathrm{~d}) T=80^{\circ} \mathrm{C}, \mathrm{MN} / \mathrm{BAD}=1, W_{\text {cat }}=50 \mathrm{mg}, t=4 \mathrm{~h}$.

should have a strong influence on the adsorption capacity of clinoptilolite. The parent zeolite, theoretically possessing the highest cation exchange capacity (CEC), but lowest external surface area, led to an adsorption of $65 \%$ of $\mathrm{Cu}^{2+}$ and $51 \%$ of MB. Sample C-A 1 displayed an adsorption half that of $\mathrm{C}-\mathrm{P}$, yielding capacities of $31 \%$ and $32 \%$ for $\mathrm{Cu}^{2+}$ and $\mathrm{MB}$, respectively. C-A1-B1 attained substantially enhanced adsorption, as $74 \%$ and $77 \%$ of the $\mathrm{Cu}^{2+}$ and $\mathrm{MB}$, respectively, were removed from the solutions. In the case of $\mathrm{MB}$ adsorption, this superior adsorption may be readily explained by the enlarged external surface. However, since $\mathrm{Cu}^{2+}$ complexes are able to enter the micropores, the increased adsorption of $\mathrm{Cu}^{2+}$ in $\mathrm{C}-\mathrm{A}_{1}-\mathrm{B}_{1}$ could be due to a largely preserved cation capacity (similar Si/Al ratio) coupled to the enhanced access provided by the secondary porosity. Also after the final dealumination $\left(\mathrm{C}-\mathrm{A}_{1}-\mathrm{B}_{1}-\mathrm{A}_{2}\right)$, the adsorption of $\mathrm{Cu}^{2+}(40 \%)$ and $\mathrm{MB}$ (45\%) was reduced, highlighting that mesoporosity introduction by dealumination does not increase the adsorption capacity of these contaminants.

The catalytic performance of clinoptilolite and L zeolites were evaluated in the alkylation of toluene with benzyl alcohol or isopropyl alcohol, and the Knoevenagel condensation of benzaldehyde with malononitrile. The yields to the desired products in these reactions are displayed in Fig. 11, while a full overview of the catalytic data is provided in Tables $\mathbf{S}_{\mathbf{5}} \mathbf{S 8}$. Similar to the adsorption experiments, the dealuminated clinoptilolite sample (CA1) performed similar or worse than the parent zeolite. Conversely, the base-treated sample displayed a superior catalytic performance for all reactions. The superiority of $\mathrm{C}-\mathrm{A}_{1}-\mathrm{B}_{1}(-\mathrm{H})$ was most pronounced in the case of the alkylation with benzyl alcohol. In the other two reactions the performance of $\mathrm{C}-\mathrm{A}_{1}-\mathrm{B}_{1}-(\mathrm{H})$ was particularly impressive when compared to $\mathrm{C}-\mathrm{A} 1$. Although being the most mesoporous, sample $\mathrm{C}-\mathrm{A}_{1}-\mathrm{B}_{1}-\mathrm{A}_{2}$ displayed a catalytic performance inferior to $\mathrm{C}-\mathrm{A}_{1}-\mathrm{B}_{1}-(\mathrm{H})$, emphasizing that the nature of secondary porosity is of crucial importance.
The conventional ZSM-5 $(\mathrm{Si} / \mathrm{Al}=15)$ showed similar activity compared to $\mathrm{C}-\mathrm{A} 1-\mathrm{B} 1-\mathrm{H}$ in the alkylation of benzyl alcohol with toluene (Table $\mathbf{S}_{5}$ ). However, since C-A1-B1$\mathrm{H}$ attained a substantially higher selectivity to (methyl)benzylbenzene (96\%) compared to ZSM-5 (83\%), a substantially higher yield of the latter product resulted for the clinoptilolite zeolite (Fig. 11a). Therefore, Based on the substantially lower price of clinoptilolite (1.5-3.5 USD $\mathrm{kg}^{-1}$ ) compared to ZSM-5 or ferrierite zeolites (10-20 USD $\left.\mathrm{kg}^{-1}\right),{ }^{2}$ hierarchical clinoptilolite may become a viable candidate for application in, for example, alkylations. Also in the case of zeolite L, dealumination alone ( $\left.\mathrm{L}-\mathrm{A}_{3}-\mathrm{H}\right)$ did not enhance the catalytic performance compared to L-P$\mathrm{H}$ (Fig. 11b). Again, the sequentially acid and base-treated sample (L-A3-B1-H) proved superior, displaying a threefold increase in conversion. Agreeing well with the proposed mechanism (Fig. 9), the final acid wash (L-A3-B1$\mathrm{A}_{4}-\mathrm{H}$ ) did not have an apparent influence on the catalytic performance.

3.6. Generalized strategies to prepare hierarchical zeolites by post-synthetic design

The majority of the recently developed post-synthetic strategies to prepare hierarchical zeolites were reported in stand-alone articles, providing deep and fundamental insights. However, at the same time, a comprehensive general understanding remains absent. This final section aims at summarizing the progress made in the design of mesoporous zeolites by demetallation and emphasizing the importance of strategically combining acid and base treatments.

The first post-synthetic modification specifically aimed at increasing zeolite utilization by introduction of a secondary network of mesopores was desilication by base leaching. This treatment, involving the partial dissolution of zeolites in aqueous $\mathrm{NaOH}$, was first reported by Young, ${ }^{49}$ and later firmly established by Ogura et al. ${ }^{50}$ and 


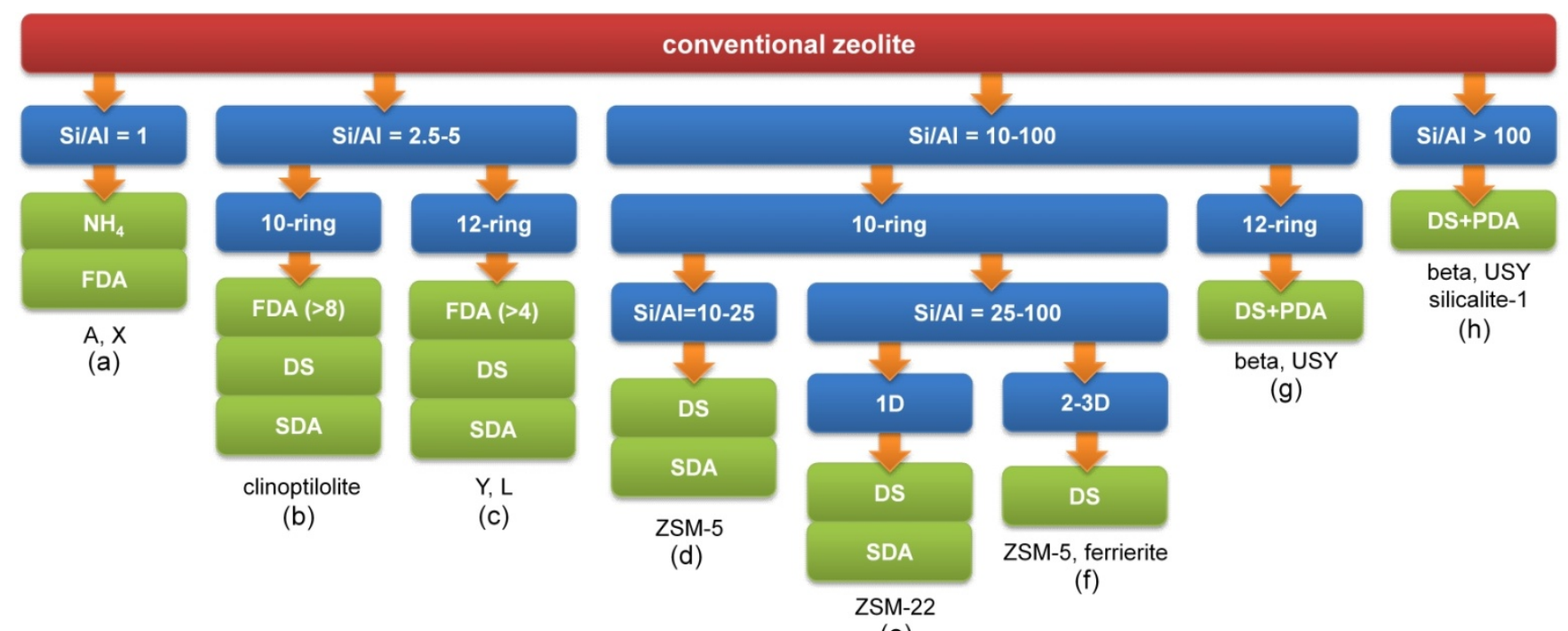

(e)

Figure 12. Overview of post-synthetic strategies (green) to turn any conventional zeolite (red) into a hierarchical zeolite. The most important features (blue) of the conventional zeolite comprise: the $\mathrm{Si} / \mathrm{Al} \mathrm{ratio,} \mathrm{micropore} \mathrm{size,} \mathrm{and} \mathrm{micropore} \mathrm{dimensional-}$ ity. Zeolites with $\mathrm{Si} / \mathrm{Al}=\mathbf{1}$ can be brought to ammonium form $\left(\mathrm{NH}_{4}\right)$, after which a controlled framework dealumination (FDA) leads to mesopore formation (a). Parent zeolites with $\mathrm{Si} / \mathrm{Al}=\mathbf{2 . 5}-5$ can be dealuminated to facilitate subsequent dissolution by desilication (DS) using a base treatment (to $\mathrm{Si} / \mathrm{Al}>8$ and $\mathrm{Si} / \mathrm{Al}>4$, for 10 and 12-ring zeolites, respectively) (b,c). For these zeolites, the removal of Al-rich debris by selective dealumination (SDA) after desilication can be of crucial importance. 10-ring zeolites in the $\mathrm{Si} / \mathrm{Al}$ range 10-100 do not readily amorphize upon base leaching (d-f), but require an additional acid wash in the case the aluminum content is high $(\mathrm{d})$ or when the dimensionality of the micropores is limited (e). 12-ring zeolites with $\mathrm{Si} / \mathrm{Al}>10$ require pore-directing agents (PDAs) in the alkaline solution to prevent amorphization and guide mesopore formation (g). Hierarchical high-silica zeolites $(\mathrm{Si} / \mathrm{Al}>100)$ are prepared by including PDAs in the alkaline solution $(\mathrm{h})$. Related references are summarized in Table S9.

Groen et al. ${ }^{22}$ Desilication was initially limited to ZSM-5 zeolites in the compositional $\mathrm{Si} / \mathrm{Al}$ range $25-50$. This major limitation sparked the development of a wide array of post-synthetic modification strategies, which have enabled the full topological and compositional flexibility. In Fig. 12 the distinct post-synthetic strategies (including this contribution) are organized based on a number of key criteria of the parent zeolites. In order of importance, these criteria comprise the $\mathrm{Si} / \mathrm{Al}$ ratio, the micropore size, and micropore dimensionality. The post-synthetic sequences include 4 different treatments:

Desilication (DS): The mesopores formed by desilication originate from a controlled (ideally intracrystalline) leaching of the zeolite framework using alkaline aqueous solutions. Although both $\mathrm{Al}$ and $\mathrm{Si}$ species are removed from the framework, the extracted aluminum is often reincorporated in the zeolite, where it acts as poredirecting agent. Base treatment using aqueous $\mathrm{NaOH}$ (in the absence of external pore-directing agents, vide infra) is suited for 10-ring zeolites with $8<\mathrm{Si} / \mathrm{Al}<100(\mathbf{b}, \mathbf{d - f})$, and for 12 -ring zeolites $4<\mathrm{Si} / \mathrm{Al}<10$ (c). Alkaline treatments require optimization, primarily in terms of alkalinity, depending among others factors on the morphology, $\mathrm{Si} / \mathrm{Al}$ ratio, and micropore size. For example, ZSM-5 (10-ring, $\mathrm{Si} / \mathrm{Al}=15)$ requires relatively severe conditions (e.g. $>0.6 \mathrm{M}$ $\mathrm{NaOH}),{ }^{47}$ while 12 -ring zeolites with similar composition necessitate only a mild alkalinity (e.g. USY: o.1 M NaOH) to induce dissolution and mesopore formation.
Desilication with external pore-directing agents $(D S+P D A)$ : The use of inorganic (soluble $\mathrm{Al}$ and Ga salts) and organic additives (tetraalkylammonium cations, TAAs) as additives to the alkaline solutions proved of high value. Because of their specific interaction with the zeolite surface under the treatment conditions they influence the degree and mechanism of dissolution, which can be exploited to tune both the mesopore size and the surface acidity. ${ }^{35,5^{1}}$ Moreover, in addition to framework Al, they exert a pore-directing role, able to direct the leaching process even within high-silica zeolites $(\mathrm{Si} / \mathrm{Al}>100, \mathbf{h})$. Finally, the addition of organic PDAs, especially TAAs, in the alkaline solution prevents framework amorphization; which is crucial in the preparation of hierarchical 12-ring zeolites with $\mathrm{Si} / \mathrm{Al}>10(\mathbf{g})$.

Selective dealumination (SDA): A prominent feature of base treatment is that when aluminum is reincorporated in the solid, it can reduce the intrinsic zeolitic properties. Especially in zeolites of low $\mathrm{Si} / \mathrm{Al}$ ratio $(<25, \mathbf{b}-\mathbf{d})$ and unidirectional micropores (e), this 'realumination' process can cause extensive blockage of micro- and mesopores. By using a subsequent mild acid wash, n.b. not aimed at the removal of aluminum in lattice positions, the deposited species can be dissolved, yielding a hierarchical zeolite with a $\mathrm{Si} / \mathrm{Al}$ ratio, crystallinity, microporosity, and acidity nearer to that of the parent sample.

Framework dealumination (FDA): Mesopore formation is not always possible by direct base treatment, due to the very slow dissolution rate of Al-rich zeolites. In this case, 
one option is to increase the $\mathrm{Si} / \mathrm{Al}$ ratio to enable subsequent dissolution by base treatment. The $\mathrm{Si} / \mathrm{Al}$ ratio required to permit efficient mesopore formation depends on the characteristic ring size of the zeolite framework, being ca. 8 in the case of 10-ring (b) and 4 for 12-ring zeolites (c). The efficiency of the initial dealumination strongly influences the impact of the subsequent alkaline treatment and the requirement for a final acid wash. ${ }^{[10]}$ Importantly, the optimized dealumination of the framework by a controlled acid leaching can also lead to extensive mesoporosity. For example, acid treatment using EDTA complexes enabled the development of mesopores in Al-rich zeolites as $\mathrm{Y}(\mathrm{Si} / \mathrm{Al}=2.4)$ and $\mathrm{X}$ and $\mathrm{A}(\mathrm{Si} / \mathrm{Al}=1.2)$ (a). In the latter cases, the type of charge balancing cation present in the zeolite was key to achieving extensive mesopore formation.

\section{Conclusions}

Hierarchical clinoptilolite and $\mathrm{L}$ zeolites were prepared using an optimized acid-base treatment sequence, attaining external surfaces up to 4 -fold that of the parent zeolite. A thorough characterization of modified clinoptilolite and L zeolites exposed the crucial role of framework dealumination as the first step in post-synthetic modification sequences: Heterogeneous $\mathrm{Al}$ distributions in the zeolite crystals formed during dealumination give rise to an inefficient desilication and make a subsequent acid wash redundant. Base leaching is highlighted as a suitable tool to, besides introducing mesoporosity, remove Si-rich debris and probe the homogeneity of the Al distribution caused by framework dealumination. Evaluation in various acid and base-catalyzed reactions demonstrated that secondary porosity introduced by framework dealumination does not yield superior performance. Conversely, the mesoporosity generated by sequential dealumination and base-leaching induced an up to 9-fold increase in the alkylation activity, while maintaining a superior selectivity. The boosted catalytic performance of hierarchical clinoptilolite rejuvenates the prospects of this zeolite as a solid catalyst. The generalized strategies underline the full topological and compositional flexibility to prepare hierarchical zeolites by harmonized post-synthetic modifications, and serve as a general guideline to facilitate their application-oriented design.

\section{ASSOCIATED CONTENT}

\section{Supporting Information}

Tables containing the yields and porous properties of all treated clinoptilolite zeolites. $\mathrm{N}_{2}$ and $\mathrm{Ar}$ isotherms and $\mathrm{Hg}$ intrusion curves of clinoptilolite and L zeolites. Extra figure with the XRD patterns of $\mathrm{L}$ zeolites. Tables summarizing the catalytic results. Table summarizing the references used to prepare Fig. 12. This material is available free of charge via the Internet at http://pubs.acs.org.

\section{AUTHOR INFORMATION}

\section{Corresponding Author}

*E-mail: jpr@chem.ethz.ch

\section{ACKNOWLEDGMENT}

ETH Zurich and the Swiss National Science Foundation (project number 200021-134572) are acknowledged for financial support. We thank Dr. S. Mitchell for TEM analyses and N. -L Michels for Hg porosimetry and SEM analyses.

\section{REFERENCES}

(1) Mumpton, F. A. Proc. Natl. Acad. Sci. USA 1999, 96, 3463.

(2) Flanigen, E. M.; Broach, R. W.; Wilson, S. T. in Zeolites in Industrial Separation and Catalysis (Ed. S. Kulprathipanja), 2010, Wiley-VCH, Weinheim, Germany, p. 17.

(3) Baerlocher, C.; McCusker, L. B. Database of Zeolite Structures, http://www.iza-structure.org/databases/ (accessed April 2013).

(4) Armbruster, T. Stud. Surf. Sci. Catal. 2oo1, 135, 13.

(5) Csicsery, S. M. Pure Appl. Chem. 1986, 58, 841.

(6) Corma, A. Chem. Rev. 1995, 95, 559.

(7) Vermeiren, W.; Gilson, J. -P. Top. Catal. 2oo9, 52, 1131.

(8) Lee, S. -H.; Shin, C. -H.; Hong, S. B. J. Catal. 2oo4, 223, 200.

(9) Seo, G.; Kim, M. -W.; Ahn, B. J.; Hong, S. B.; Uh, Y. S. Catal. Lett. 1998, 55, 105.

(10) Mooiweer, H. H.; de Jong, K. P.; Kraushaar-Czarnetzki, B.; Stork, W. H. J.; Krutzen, B. C. H. Stud. Surf. Sci. Catal. 1994, 84, 2327.

(11) Bedard, R. L. in Zeolites in Industrial Separation and Catalysis (Ed. S. Kulprathipanja), 2010, Wiley-VCH, Weinheim, Germany, pp. 72-73.

(12) Verboekend, D.; Pérez-Ramírez, J. Catal. Sci. Technol. 2011, $1,879$.

(13) Pérez-Ramírez, J. Nat. Chem. 2012, 4, 250.

(14) Pérez-Ramírez, J.; Christensen, C. H.; Egeblad, K.; Christensen, C. H.; Groen, J. C. Chem. Soc. Rev. 20o8, 37, 2530.

(15) Lopez-Orozco, S.; Inayat, A.; Schwab, A.; Selvam, T.; Schwieger, W. Adv. Mater. 2011, 23, 2602.

(16) Chal, R.; Gérardin, C.; Bulut, M.; van Donk, S. ChemCatChem 2011, 3, 67.

(17) Martínez, C.; Verboekend, D.; Pérez-Ramírez, J.; Corma, A. Catal. Sci. Technol. 2013, 3, 972.

(18) Martens, J. A.; Verboekend, D.; Thomas, K.; Vanbutsele, G.; Gilson, J. -P.; Pérez-Ramírez, J. ChemSusChem, 2013, 6, 421.

(19) Verboekend, D.; Keller, T. C.; Mitchell, S.; Pérez-Ramírez, J. Adv. Funct. Mater. 2013, DOI: 10.1002/adfm.20120232022.

(20) van Laak, A. N. C.; Sagala, S. L.; Zečević, J.; Friedrich, H.; de Jongh, P. E.; de Jong, K. P. J. Catal. 2010, 276, 170.

(21) Verboekend, D.; Vilé, G.; Pérez-Ramírez, J. Adv. Funct. Mater. 2012, 22, 916.

(22) Groen, J. C.; Peffer, L. A. A.; Moulijn, J. A.; Pérez-Ramírez, J. Chem. Eur. J. 2005, 11, 4983.

(23) Čižmek, A.; Subotić, B.; Šmit, I.; Tonejc, A.; Aiello, R.; Crea, F.; Nastro, A. Microporous Mater. 1997, 8, 159.

(24) Dessau, R. M.; Valyocsik, E. W.; Goeke, N. H. Zeolites 1992, 12,776

(25) Groen, J. C.; Bach, T.; Ziese, U.; Paulaime-van Donk, A. M.; de Jong, K. P.; Moulijn, J. A.; Pérez-Ramírez, J. J. Am. Chem. Soc. 2005, 127, 10792.

(26) Barrer, R. M.; Makki, B. M. Can. J. Chem. 1964, 42, 1481.

(27) Garcia-Basabe, Y.; Rodriguez-Iznaga, I.; de Menorval, L. -C.; Llewellyn, P.; Maurin, G.; Lewis, D. W.; Binions, R.; Autie, M.; Ruiz-Salvador, A. R. Microporous Mesoporous Mater. 2010, 135,187 .

(28) Sprynskyy, M.; Golembiewsmi, R.; Trykowski, G.; Buszewski, B. J. Phys. Chem. Solids 2010, 71, 1269.

(29) Lee, H. C.; Woo, H. C.; Ryoo, R.; Lee, K. H.; Lee, J. S. Appl. Catal. A 2000, 196, 135. 
(30) Akgül, M.; Karabakan, A. Microporous Mesoporous Mater. 2011, $145,157$.

(31) Jentoft, R. E.; Tsapatsis, M.; Davis, M. E.; Gates, B. C. J. Catal. 1998, 179, 565 .

(32) http://www.kmizeolite.com/ (accessed April 2013)

(33) Breck, D. W.; Skeels, G. W. US4503023, 1985.

(34) Detreköy, E. J.; Jacobs, P. A.; Kalló, D.; Uytterhoeven, J. B. J. Catal. 1974, 32, 442.

(35) Bonilla, A.; Baudouin, D.; Pérez-Ramírez, J. J. Catal. 2009, 265, 170.

(36) Verboekend, D.; Chabaneix, A. M.; Thomas, K.; Gilson, J. -P.; Pérez-Ramírez, J. CrystEngComm 2o11, 13, 3408.

(37) Nesterenko, N. S.; Thibault-Starzyk, F.; Montouillout, V.; Yuschenko, V. V.; Fernandez, C.; Gilson, J. -P.; Fajula, F.; Ivano-

va, I. I. Microporous Mesoporous Mater. 2004, 71, 157.

(38) Townsend, R. P.; Loizidou, M. Zeolites 1984, 4, 191.

(39) Verboekend, D.; Vilé, G.; Pérez-Ramírez, J. Cryst. Growth Des. 2012, 12, 3123.

(40) Chen, H.; Wydra, J.; Zhang, X.; Lee, P. -S.; Wang, Z.; Fan, W.; Tsapatsis, M. J. Am. Chem. Soc. 2011, 133, 12390.

(41) Huo, Q.; Dou, T.; Zhao, Z.; Pan. H. Appl. Catal. A 2010, 381, 101.

(42) Beyer, H. K. in Molecular Sieves, Vol. 3, Springer-Verlag, Berlin, Germany 20o2. pp. 226-235.

(43) Bartl, P.; Hölderich, W. F. Microporous Mesoporous Mater. 200o, $38,279$.

(44) Wang, Q. L.; Torreabla, M.; Giannetto, G.; Guisnet, M.; Perot, G.; Cahoreau, M.; Caisso, J. Zeolites 1990, 10, 703.

(45) Moreno, S.; Poncelet, G. Microporous Mater. 1997, 12, 197.

(46) Akporiaye, D.; Clark, D. M.; Dwyer, J.; Elliott, I. S.; Rawlence, D. J.; Chapple, A. P. Stud. Surf. Sci. Catal. 1986, 28, 351. (47) Verboekend, D.; Mitchell, S.; Milina, M.; Groen, J. C.; Pérez-Ramirez, J. J. Phys. Chem. C 2011, 115, 14193.

(48) Verboekend, D.; Pérez-Ramírez, J. Chem. Eur. J. 2011, 17, 1137.

(49) Young, D. A. US3326797, 1967.

(50) Ogura, M.; Shinomiya, S. -Y.; Tateno, J.; Nara, Y.; Kikuchi, E.; Matsukata, M. Chem. Lett. 2ooo, 882.

(51) Pérez-Ramírez, J.; Verboekend, D.; Bonilla, A.; Abelló, S. Adv. Funct. Mater. 2009, 19, 3972. 
Table of Contents artwork

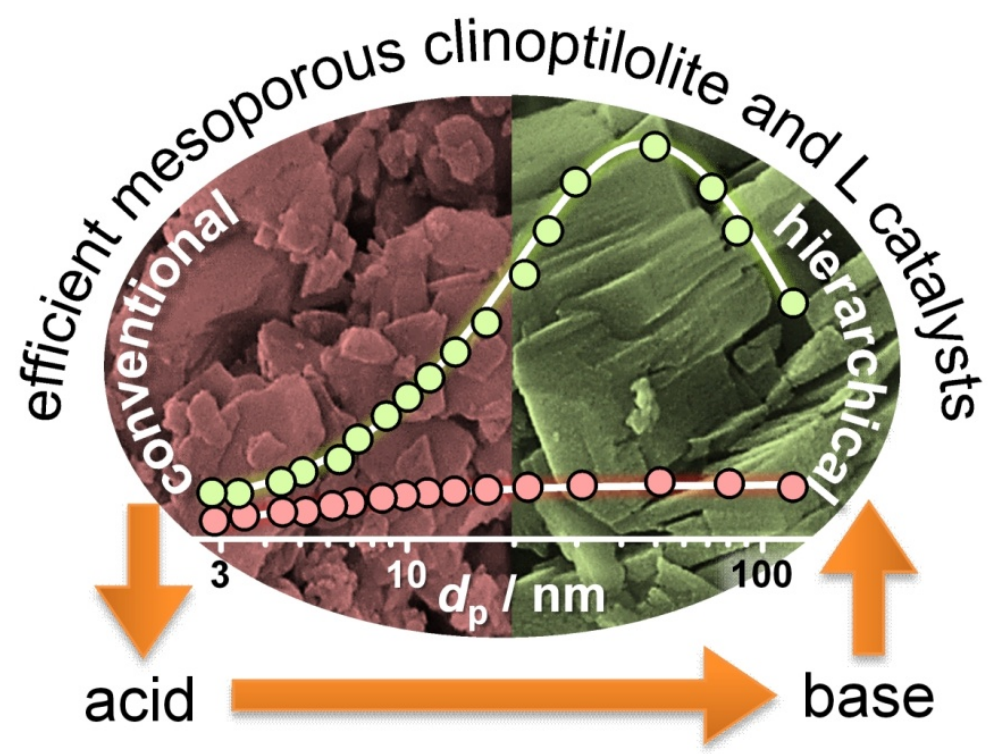




\title{
Supporting information
}

\section{Hierarchy Brings Function: Mesoporous Clinoptilolite and L Zeolite Catalysts Synthesized by Tandem Acid-Base Treatments}

\author{
Danny Verboekend, Tobias C. Keller, Maria Milina, Roland Hauert, \\ and Javier Pérez-Ramírez
}

Table S1. Sample notation and treatment conditions.

\begin{tabular}{lcccccc}
\hline Treatment & Reagent $(\%)$ & $C(\mathrm{M})$ & $C_{\text {zeolite }}\left(\mathrm{g} \mathrm{L}^{-1}\right)$ & $T\left({ }^{\circ} \mathrm{C}\right)$ & $t(\mathrm{~h})$ & Repetitions (\#) \\
\hline A1 & $\mathrm{HCl}$ & 1 & 67 & 100 & 4 & 4 \\
$\mathrm{~A} 2$ & $\mathrm{HCl}$ & 1 & 67 & 100 & 4 & 1 \\
$\mathrm{~A} 5$ & $\mathrm{HCl}$ & 1.5 & 67 & 100 & 4 & 1 \\
$\mathrm{~A} 6$ & $\mathrm{HCl}$ & 2 & 67 & 100 & 4 & 1 \\
A7 & $\mathrm{HCl}$ & 1 & 67 & 100 & 4 & 2 \\
A8 & $\mathrm{HCl}$ & 1 & 67 & 100 & 4 & 3 \\
$\mathrm{~B} 1$ & $\mathrm{NaOH}$ & 0.2 & 33 & 65 & 0.5 & 1 \\
$\mathrm{~B} 2$ & $\mathrm{NaOH}$ & 0.4 & 33 & 65 & 0.5 & 1 \\
$\mathrm{~B} 3$ & $\mathrm{NaOH}$ & 1.0 & 33 & 65 & 0.5 & 1 \\
B4 & $\mathrm{NaOH}$ & 0.1 & 33 & 65 & 0.5 & 1 \\
\hline
\end{tabular}

Table S2. Yield and porosity of alkaline-treated clinoptilolite zeolites.

\begin{tabular}{lccccc}
\hline Sample & Yield (\%) & $V_{\text {micro }}{ }^{a}\left(\mathrm{~cm}^{3} \mathrm{~g}^{-1}\right)$ & $V_{\text {meso }}{ }^{\mathrm{b}}\left(\mathrm{cm}^{3} \mathrm{~g}^{-1}\right)$ & $V_{\text {pore }}{ }^{\mathrm{c}}\left(\mathrm{cm}^{3} \mathrm{~g}^{-1}\right)$ & $S_{\text {meso }}{ }^{\mathrm{a}}\left(\mathrm{m}^{2} \mathrm{~g}^{-1}\right)$ \\
\hline C-P & - & 0 & 0.05 & 0.05 & 15 \\
C-B1 & 93 & 0 & 0.06 & 0.06 & 14 \\
C-B2 & 93 & 0 & 0.05 & 0.05 & 16 \\
C-B3 & 89 & 0 & 0.07 & 0.07 & 16 \\
C-B4 & 94 & 0 & 0.05 & 0.05 & 14 \\
\hline
\end{tabular}

${ }^{\mathrm{a}}$ t-plot method. ${ }^{\mathrm{b}} V_{\text {meso }}=V_{\text {pore }}-V_{\text {micro }}{ }^{\mathrm{c}}$ Volume adsorbed at $p / p_{0}=0.99$. 
Table S3. Yield and porosity of acid-treated clinoptilolite zeolites.

\begin{tabular}{lccccc}
\hline Sample & Yield (\%) & $V_{\text {micro }}\left(\mathrm{cm}^{3} \mathrm{~g}^{-1}\right)$ & $V_{\text {meso }}{ }^{\mathrm{b}}\left(\mathrm{cm}^{3} \mathrm{~g}^{-1}\right)$ & $V_{\text {pore }}{ }^{\mathrm{c}}\left(\mathrm{cm}^{3} \mathrm{~g}^{-1}\right)$ & $S_{\text {meso }}{ }^{\mathrm{a}}\left(\mathrm{m}^{2} \mathrm{~g}^{-1}\right)$ \\
\hline C-P & - & 0 & 0.05 & 0.05 & 15 \\
C-A2 & 81 & 0.08 & 0.06 & 0.14 & 39 \\
C-A5 & 83 & 0.10 & 0.06 & 0.16 & 40 \\
C-A6 & 84 & 0.10 & 0.06 & 0.16 & 41 \\
C-A1 & $100^{\mathrm{d}}(71)^{\mathrm{e}}$ & 0.13 & 0.10 & 0.23 & 63 \\
C-A7 & $91^{\mathrm{d}}(74)$ & 0.12 & 0.07 & 0.19 & 48 \\
C-A8 & $97^{\mathrm{d}}(71)$ & 0.13 & 0.08 & 0.21 & 61 \\
\hline
\end{tabular}

${ }^{\mathrm{a}} t$-plot method. ${ }^{\mathrm{b}} V_{\text {meso }}=V_{\text {pore }}-V_{\text {micro. }}{ }^{\mathrm{c}}$ Volume adsorbed at $p / p_{0}=0.99 .{ }^{\mathrm{d}}$ Yield of the last repetition, see Table S1. ${ }^{e}$ Overall yield in parentheses.

Table S4. Yield and porosity of acid- and alkaline-treated clinoptilolite zeolites.

\begin{tabular}{lccccc}
\hline Sample & Yield (\%) & $V_{\text {micro }}{ }^{\mathrm{a}}\left(\mathrm{cm}^{3} \mathrm{~g}^{-1}\right)$ & $V_{\text {meso }}{ }^{\mathrm{b}}\left(\mathrm{cm}^{3} \mathrm{~g}^{-1}\right)$ & $V_{\text {pore }}{ }^{\mathrm{c}}\left(\mathrm{cm}^{3} \mathrm{~g}^{-1}\right)$ & $S_{\text {meso }}{ }^{\mathrm{a}}\left(\mathrm{m}^{2} \mathrm{~g}^{-1}\right)$ \\
\hline C-P & - & 0 & 0.05 & 0.05 & 15 \\
C-A2-B1 & $77(62)^{\mathrm{d}}$ & 0 & 0.13 & 0.13 & 32 \\
C-A5-B1 & $69(57)$ & 0 & 0.16 & 0.16 & 29 \\
C-A6-B1 & $70(59)$ & 0 & 0.17 & 0.17 & 32 \\
C-A7-B1 & $59(44)$ & 0.01 & 0.17 & 0.18 & 35 \\
C-A8-B1 & $58(41)$ & 0.01 & 0.19 & 0.20 & 47 \\
C-A1-B1 & $57(41)$ & 0 & 0.25 & 0.25 & 64 \\
C-A1-B2 & $57(41)$ & 0 & 0.24 & 0.24 & 46 \\
C-A1-B4 & $83(59)$ & 0 & 0.18 & 0.18 & 84 \\
C-A1-B1-A2 & $89(37)$ & 0.10 & 0.32 & 0.42 & 103 \\
C-A1-B2-A2 & $82(34)$ & 0.11 & 0.26 & 0.37 & 74 \\
C-A1-B4-A2 & $88(52)$ & 0.11 & 0.18 & 0.29 & 113 \\
\hline
\end{tabular}

${ }^{\mathrm{a}} t$-plot method. ${ }^{\mathrm{b}} V_{\text {meso }}=V_{\text {pore }}-V_{\text {micro. }}{ }^{c}$ Volume adsorbed at $p / p_{0}=0.99 .{ }^{\mathrm{d}}$ Overall yield in parentheses. 
Table S5. Performance of clinoptilolite and ZSM-5 zeolites in the alkylation of toluene (T) with benzyl alcohol (BA). Conditions: $T=180^{\circ} \mathrm{C}, \mathrm{T} / \mathrm{BA}=80, W_{\text {cat }}=25 \mathrm{mg}$.

\begin{tabular}{|c|c|c|c|c|c|c|c|c|}
\hline \multirow[b]{2}{*}{ Sample } & \multicolumn{4}{|c|}{$t=2 \mathrm{~h}$} & \multicolumn{4}{|c|}{$t=3 \mathrm{~h}$} \\
\hline & $X_{\mathrm{BA}^{\mathrm{a}}}(\%)$ & $S_{\mathrm{MBB}}^{\mathrm{b}}(\%)$ & $S_{\mathrm{BE}}^{\mathrm{c}}(\%)$ & $Y_{\mathrm{MBB}}{ }^{\mathrm{d}}(\%)$ & $X_{\mathrm{BA}}{ }^{a}(\%)$ & $S_{\mathrm{MBB}}^{\mathrm{b}}(\%)$ & $S_{\mathrm{BE}}^{\mathrm{c}}(\%)$ & $Y_{\mathrm{MBB}}{ }^{\mathrm{d}}(\%)$ \\
\hline C-P-H & 7 & 100 & 0 & 7 & 8 & 100 & 0 & 8 \\
\hline C-A1 & 6 & 100 & 0 & 6 & 6 & 100 & 0 & 6 \\
\hline C-A1-B1-H & 96 & 89 & 11 & 85 & 100 & 96 & 4 & 96 \\
\hline C-A1-B1-A2 & 33 & 80 & 20 & 26 & 71 & 84 & 16 & 60 \\
\hline ZSM-5 & 80 & 76 & 24 & 61 & 97 & 83 & 17 & 81 \\
\hline
\end{tabular}

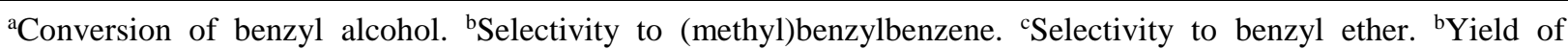
(methyl)benzylbenzene, $Y_{\mathrm{MBB}}=X_{\mathrm{BA}} \times S_{\mathrm{MBB}}$.

Table S6. Performance of $\mathrm{L}$ zeolites in the alkylation of toluene (T) with benzyl alcohol (BA). Conditions: $T=130^{\circ} \mathrm{C}, \mathrm{T} / \mathrm{BA}=80, W_{\text {cat }}=25 \mathrm{mg}, t=0.5 \mathrm{~h}$.

\begin{tabular}{lcccc}
\hline Sample & $\left.X_{\mathrm{BA}^{\mathrm{a}}}{ }^{\mathrm{a}} \%\right)$ & $S_{\mathrm{MBB}^{\mathrm{b}}}(\%)$ & $S_{\mathrm{BE}^{\mathrm{c}}}(\%)$ & $Y_{\mathrm{MBB}}{ }^{\mathrm{d}}(\%)$ \\
\hline L-P-H & 18 & 79 & 21 & 14 \\
L-A3-H & 20 & 84 & 16 & 17 \\
L-A3-B1-H & 85 & 89 & 12 & 76 \\
L-A3-B1-A4-H & 84 & 89 & 11 & 75 \\
\hline
\end{tabular}

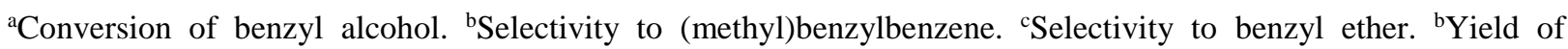
(methyl)benzylbenzene, $Y_{\mathrm{MBB}}=X_{\mathrm{BA}} \times S_{\mathrm{MBB}}$.

Table S7. Performance of clinoptilolite zeolites in the alkylation of toluene $(\mathrm{T})$ with isopropyl alcohol (IPA). Conditions: $T=180^{\circ} \mathrm{C}, \mathrm{T} / \mathrm{IPA}=40, W_{\text {cat }}=50 \mathrm{mg}, t=20 \mathrm{~h}$.

\begin{tabular}{lcccc}
\hline Sample & $X_{\mathrm{IPA}^{\mathrm{a}}}{ }^{(\%)}$ & $S_{\mathrm{cym}}{ }^{\mathrm{b}}(\%)$ & $S_{\mathrm{PP}^{\mathrm{c}}}(\%)$ & $Y_{\mathrm{cym}}{ }^{\mathrm{d}}(\%)$ \\
\hline C-P-H & 67 & 2.8 & 97.2 & 1.9 \\
C-A1 & 62 & 0.3 & 99.7 & 0.2 \\
C-A1-B1-H & 100 & 5.9 & 94.1 & 5.9 \\
C-A1-B1-A2 & 100 & 2.2 & 97.8 & 2.2 \\
\hline
\end{tabular}

${ }^{\mathrm{a}}$ Conversion of isopropyl alcohol. ${ }^{\mathrm{b}}$ Selectivity to cymenes. 'Selectivity to propene. ${ }^{\mathrm{b}}$ Yield of cymenes, $Y_{\text {cym }}=X_{\mathrm{IPA}} \times S_{\text {cym. }}$. 
Table S8. Performance of clinoptilolite zeolites in the Knoevenagel condensation of benzaldehyde (BAD) with malononitrile (MN). Conditions: $T=80^{\circ} \mathrm{C}, \mathrm{MN} / \mathrm{BAD}=1, W_{\text {cat }}=50 \mathrm{mg}, t=4 \mathrm{~h}$.

\begin{tabular}{lccc}
\hline Sample & $X_{\mathrm{BAD}^{\mathrm{a}}}(\%)$ & $S_{\mathrm{BMN}^{\mathrm{b}}}(\%)$ & $Y_{\mathrm{BMN}^{\mathrm{c}}}(\%)$ \\
\hline C-P-H & 26 & 93 & 24 \\
C-A1 & 8 & 95 & 8 \\
C-A1-B1-H & 39 & 96 & 38 \\
C-A1-B1-A2 & 13 & 95 & 12 \\
\hline
\end{tabular}

${ }^{a}$ Conversion of benzaldehyde. ${ }^{b}$ Selectivity to benzylidenemalononitrile. ${ }^{c}$ Yield of benzylidenemalononitrile, $Y_{\mathrm{BMN}}=X_{\mathrm{BAD}} \times S_{\mathrm{BMN}}$.

Table S9. Key contributions in the preparation of hierarchical zeolites by post-synthetic design.

\begin{tabular}{lccccc}
\hline Zeolite & Framework & Si/Al (-) & Micropore size (MR) & Micropore dimensionality & Reference \\
\hline ZSM-5 & MFI & $25-50$ & 10 & 3 & 1 \\
ferrierite & FER & 29 & $\leq 10$ & 2 & 2 \\
silicalite-1 & MFI & 1320 & 10 & 3 & 3 \\
ZSM-22 & TON & 42 & 10 & 1 & 4 \\
ZSM-5 & MFI & $10-25$ & 10 & 3 & 5 \\
Y & FAU & 2.4 & 12 & 3 & 6 \\
USY & FAU & $15-385$ & 12 & 3 & 6,7 \\
beta & BEA & 220 & 12 & 3 & 7 \\
A & LTA & 1 & 8 & 3 & 8 \\
X & FAU & 1 & 12 & 3 & 8 \\
clinoptilolite & HEU & 5.2 & $\leq 10$ & 2 & this work \\
L & LTL & 2.9 & 12 & 1 & this work \\
\hline
\end{tabular}

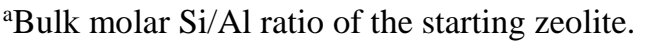

(1) J. C. Groen, L. A. A. Peffer, J. A. Moulijn, J. Pérez-Ramírez, Chem. Eur. J. 2005, 11, 4983.

(2) A. Bonilla, D. Baudouin, J. Pérez-Ramírez, J. Catal. 2009, 265, 170.

(3) D. Verboekend, J. Pérez-Ramírez, Chem. Eur. J. 2011, 17, 1137.

(4) D. Verboekend, A. M. Chabaneix, K. Thomas, J.-P. Gilson, J. Pérez-Ramírez CrystEngComm 2011, 13, 3408.

(5) D. Verboekend, S. Mitchell, M. Milina, J. C. Groen, J. Pérez-Ramirez, J. Phys. Chem. C 2011, 115, 14193.

(6) D. Verboekend, G. Vilé, J. Pérez-Ramírez, Adv. Funct. Mater. 2012, 22, 916.

(7) D. Verboekend, G. Vilé, J. Pérez-Ramírez, Cryst. Growth Des. 2012, 12, 3123.

(8) D. Verboekend, T. C. Keller, S. Mitchell, J. Pérez-Ramírez, Adv. Funct. Mater. 2013, DOI: 10.1002/adfm.20120232022. 


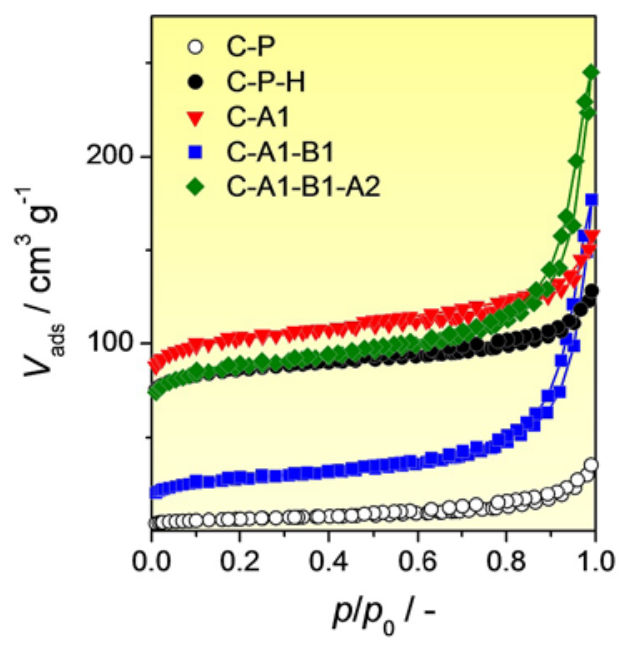

Figure S1. Nitrogen isotherms of clinoptilolite zeolites.
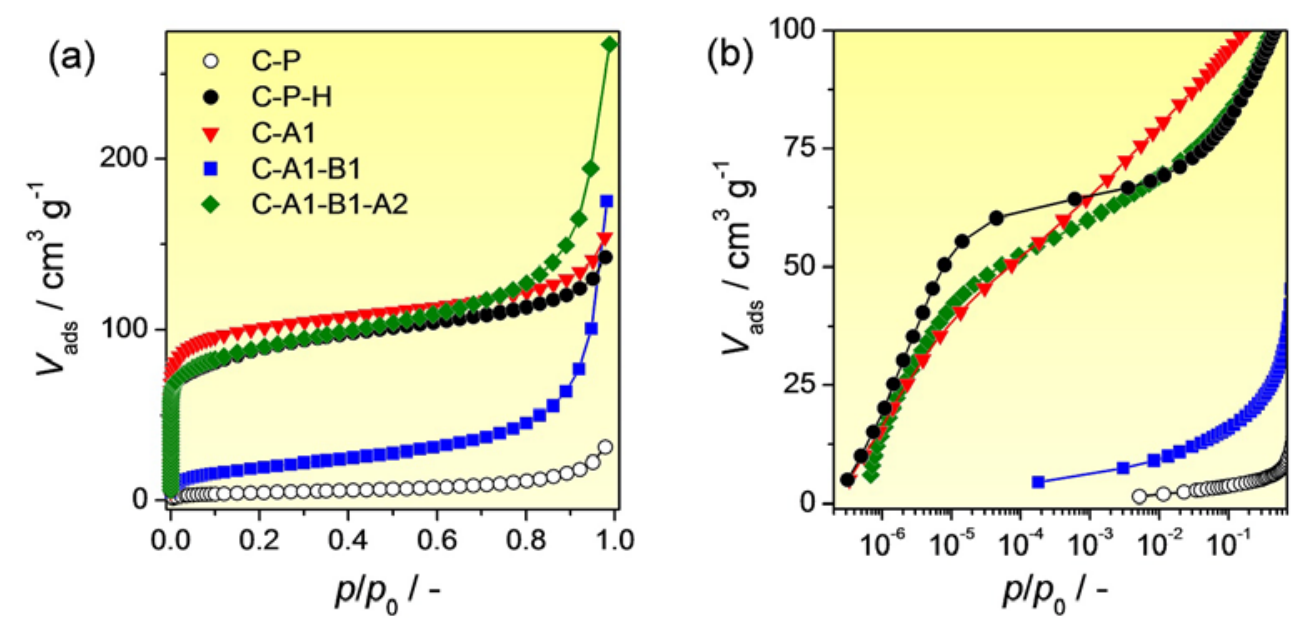

Figure S2. Argon isotherms of clinoptilolite zeolites.
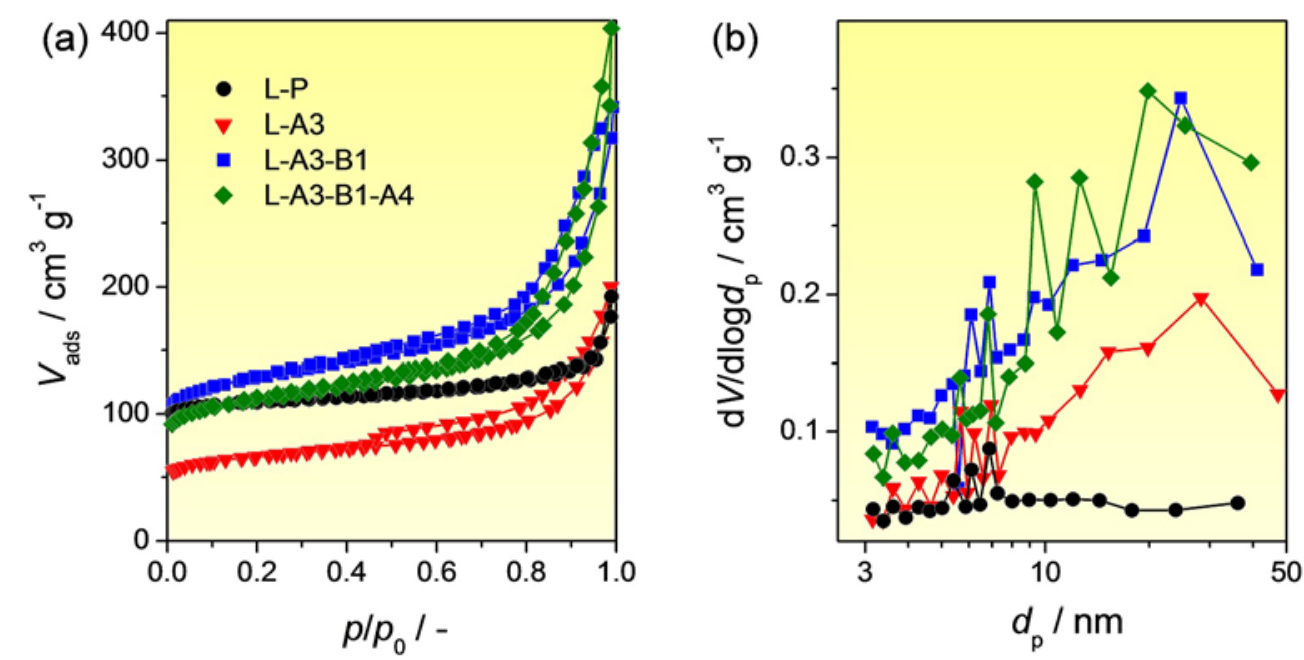

Figure S3. (a) Nitrogen isotherms of L zeolites and (b) derived BJH mesopore size distributions. 


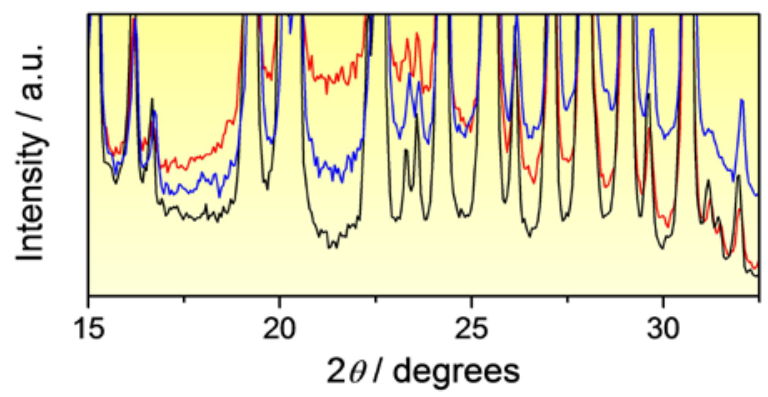

Figure S4. X-ray diffraction patterns of L zeolites. From top to bottom, at 22 $2 \theta$ : L-A3, L-A3-B1, and L-P.

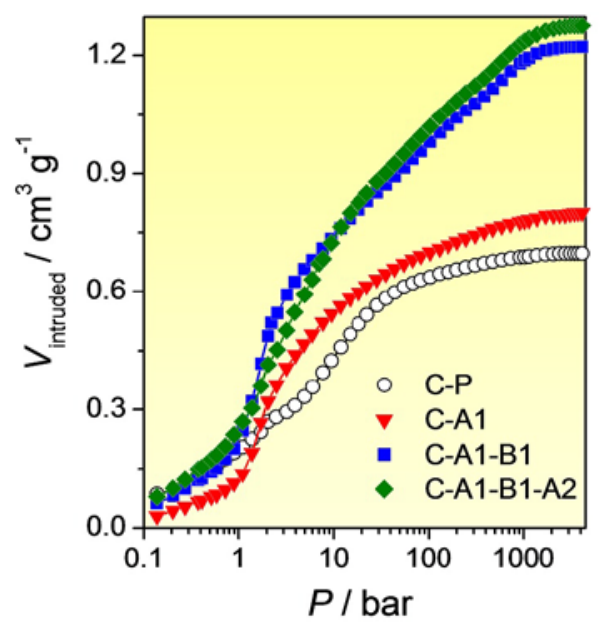

Figure S5. Mercury intrusion curves of clinoptilolite zeolites. 